Title: HCN1 channels mediate mu opioid receptor long-term depression at insular

${ }^{2}$ Stark Neurosciences Research Institute, Indiana University School of Medicine,

Indianapolis, IN, 46202, USA.

\title{
Author Contact information
}

Corresponding author: Brady K. Atwood, PhD.

11 Indiana University School of Medicine

12 Department of Pharmacology \& Toxicology

$13320 \mathrm{~W} 15$ th St.

14 NB 400C

15 Indianapolis, IN, USA 46202

16 Tel: 317-274-8917

17 Fax: 317-274-7714 


\section{Abstract}

21

22 opioid receptor, insular cortex, HCN1 channel. and opioid use disorders.

Mu opioid receptors (MORs) are expressed in the dorsal striatum, a brain region that mediates goal-directed (via the dorsomedial striatum), and habitual (via the dorsolateral striatum, DLS) behaviors. Our previous work indicates that glutamate transmission is depressed when MORs are activated in the dorsal striatum, inducing MOR-mediated long-term synaptic depression (MOR-LTD) or short-term depression (MOR-STD), depending on the input. In the DLS, MOR-LTD is produced by MORs on anterior insular cortex (AIC) inputs and MOR-STD occurs at thalamic inputs, suggesting input-specific MOR plasticity mechanisms. Here, we evaluated the mechanisms of induction of MORLTD and MOR-STD in the DLS using pharmacology and optogenetics combined with patch clamp electrophysiology. We found that cAMP/PKA signaling and protein synthesis are necessary for MOR-LTD expression, similar to previous studies of endocannabinoid-mediated LTD (eCB-LTD) in DLS. However, MOR-LTD does not require mTOR signaling as eCB-LTD does. MOR-STD does not utilize these same mechanisms. We characterized the role of presynaptic HCN1 channels in MOR-LTD induction as HCN1 channels expressed in AIC are necessary for MOR-LTD expression in the DLS. These results suggest a mechanism in which MOR activation needs HCN1 to induce MOR-LTD, suggesting a new target for pharmacological modulation of synaptic plasticity, providing new opportunities to develop novel drugs to treat alcohol

Keywords: synaptic plasticity, long-term depression, dorsal striatum, corticostriatal, mu 2 
43

44

45

46

47

\section{Introduction}

The opioid system is expressed throughout the brain(Le Merrer, Becker, Befort, \& Kieffer, 2009) and promotes synaptic plasticity in many brain regions(Bao et al., 2007; Dacher \& Nugent, 2011a, 2011b; Drake, Chavkin, \& Milner, 2007; Iremonger \& Bains, 2009), including the dorsal striatum (DS)(Atwood, Kupferschmidt, \& Lovinger, 2014; Hawes, Salinas, Lovinger, \& Blackwell, 2017; Lovinger, 2010; Munoz, Fritz, Yin, \& Atwood, 2018; Muñoz, Haggerty, \& Atwood, 2020). The DS is the primary input nucleus of the basal ganglia and can be subdivided in two structures: the dorsomedial striatum (DMS), which controls goal-directed learning, and the dorsolateral striatum (DLS), which regulates habit formation(Burton, Nakamura, \& Roesch, 2015; Corbit \& Janak, 2016; Hilário \& Costa, 2008; Lovinger, 2010; O'Tousa \& Grahame, 2014). Drug and alcohol use shift from being outcome-driven to becoming more stimulus-driven and compulsive in nature during addiction development(Corbit \& Janak, 2016; Everitt \& Robbins, 2016; Hopf \& Lesscher, 2014; Shen et al., 2018). This transition from flexible goal-directed drug use to more habitual or compulsive use, is paralleled by a transition in the neural activity from the DMS to the DLS(Corbit \& Janak, 2016; Renteria, Cazares, \& Gremel, 2020; Shen et al., 2018), thereby shifting the balance of action control from DMS to DLS. Previous reports have demonstrated the role of glutamatergic synaptic plasticity in behavior, showing that the disruption of glutamatergic long-term synaptic depression (LTD) at orbitofrontal cortex-DMS synapses prevents habit learning(Gremel et al., 2016), and the disruption of glutamatergic LTD in DLS promotes habit learning(DePoy et al., 2013; C. Nazzaro et al., 2012). Therefore, changes in the expression of excitatory synaptic plasticity affect specific DS-related behaviors. 
Our previous work established that mu opioid receptor (MOR) activation induces long-

67 term synaptic depression (MOR-LTD) or short-term depression (MOR-STD) of glutamate release in both the DLS and DMS(Atwood, Kupferschmidt, et al., 2014; Munoz et al., 2018; Muñoz et al., 2020). We demonstrated that MOR-mediated synaptic inhibition is expressed at multiple DS synapses (cortical, thalamic, amygdala and cholinergic), but only a subset of corticostriatal synapses expressed MOR-LTD(Atwood, Kupferschmidt, et al., 2014) that was disrupted by prior in vivo ethanol exposure(Munoz et al., 2018; Muñoz et al., 2020). We also found that mice that were exposed to alcohol and the opioid oxycodone in vivo had ablated corticostriatal MOR-LTD when measured in brain slices(Atwood, Kupferschmidt, et al., 2014; Munoz et al., 2018; Muñoz et al., 2020) MOR plasticity at other DS synapses was unaffected by alcohol exposure(Munoz et al., 2018; Muñoz et al., 2020). Of particular interest, in DLS, alcohol and opioidsensitive MOR-LTD of glutamatergic input is completely restricted to anterior insular cortex (AIC) inputs(Atwood, Kupferschmidt, et al., 2014; Munoz et al., 2018). Altogether,

these data led us to hypothesize that MOR plasticity utilizes different mechanisms at

81 distinct glutamatergic synapses in DS. As we previously demonstrated that MOR-LTD

82 and endocannabinoid LTD (eCB-LTD) are mutually occlusive in DS(Atwood,

83 Kupferschmidt, et al., 2014), we predicted that these two forms of LTD would utilize

84 similar mechanisms. CAMP/PKA signaling mediates eCB-LTD in the nucleus

85 accumbens, amygdala, cerebellum, and hippocampus(Atwood, Lovinger, \& Mathur, 2014). In addition, local protein translation in the presynaptic region is enhanced by the activation of CB1 receptor, which is important for the induction of inhibitory LTD in the 88 hippocampus(Younts et al., 2016) and likely also in the DS(Yin, Davis, Ronesi, \& 
Lovinger, 2006). eCB-LTD at GABAergic synapses in the hippocampus is also mediated by mTOR signaling(Younts et al., 2016). Therefore, we sought to test whether MORLTD in DLS, and specifically at AIC-DLS synapses is mediated by CAMP/PKA, protein

92 translation and mammalian target of rampamycin (mTOR) signaling. As cAMP also regulates hyperpolarization-activated cyclic nucleotide-gated (HCN) channels, these

94 channels can presynaptically regulate glutamate release, and the type $1 \mathrm{HCN}$ (HCN1) channel may be localized to corticostriatal neurons, we also explored a potential role for HCN1 in mediating MOR-LTD in DLS(He, Chen, Li, \& Hu, 2014; Z. Huang, Li, Aguado, Lujan, \& Shah, 2017; Moosmang, Biel, Hofmann, \& Ludwig, 1999; Postea \& Biel, 2011)

In the current study, we probed glutamatergic synapses in the DLS using ex vivo mouse brain slice electrophysiology. We used broad electrical stimulation in C57BL/6J mice to test all glutamatergic inputs. We used an optogenetics approach to probe specific glutamate synapses in DLS, using Emx1-Ai32 mice to test all cortical inputs, VGluT2Ai32 mice to test all thalamic inputs, and C57BL/6J mice stereotaxically injected with an AAV-ChR2 vector into the AIC to specifically probe AIC-DLS synapses. In combination with these tools, we pharmacologically and genetically probed the mechanism involved in the expression of MOR-LTD in the DLS. We demonstrate that CAMP/PKA signaling 106 and protein synthesis are necessary for MOR-LTD expression, but not for MOR-STD. We describe a novel role of presynaptic AIC HCN1 channels in the induction of MORLTD in DLS. We also report that mTOR signaling is required for eCB-LTD of glutamate transmission in the DLS, but this is not required for MOR-LTD indicating a divergence in the mechanisms of these two similar forms of synaptic plasticity. 
112

113

114

115

116

117

118

119

120

121

122

123

124

125

126

127

128

129

130

131

132

133

134

\section{Results}

\section{MOR activation express glutamatergic LTD in the DLS}

We previously showed that the activation of MOR in DLS produces LTD of eEPSCs as well as oEPSCs(Munoz et al., 2018). Using three approaches, we confirmed that $5 \square$ min application of the MOR agonist DAMGO $(0.3 \square \mu \mathrm{M})$ induces MOR-LTD. We found that DAMGO produced a persistent decrease in eEPSC amplitude in DLS MSNs (72 $\pm 5 \%$; Figure $1 A-D)$ in brain slices from $\mathrm{C} 57 \mathrm{BI} / 6 \mathrm{~J}$ mice. To generally probe corticostriatal synapses, we used $470 \mathrm{~nm}$ light delivered through the microscope objective to evoke oEPSCs in brain slices from Emx1-Ai32 mice (Figure 1E), where the activation of MOR again induced MOR-LTD (71 $\pm 5 \%$; Figure 1F-H). Finally, to specifically stimulate the release of glutamate from AIC inputs to the DLS, we infused an AAV vector expressing ChR2 in the AIC (Figure 1I), as we previously did(Munoz et al., 2018). As shown previously, activation of MORs produced glutamatergic LTD of AIC-DLS transmission (66 $\pm 7 \%$; Figure $1 \mathrm{~J}-\mathrm{L})$. We also confirmed that thalamostriatal inputs expressed MORSTD in the DLS using VGluT2-Ai32 transgenic mice (15-20 min: $70 \pm 9 \% ; 30-40$ min: 93 $\pm 9 \%$; Figure supplement $1 A-B$ ) as we previously showed(Atwood, Kupferschmidt, et al., 2014; Munoz et al., 2018). These data replicate our previous work that MORs mediated LTD of AIC-DLS synapses and STD of thalamostriatal synapses in the DLS. We previously showed that eCB-LTD and MOR-LTD were mutually occlusive in DLS(Atwood, Kupferschmidt, et al., 2014). In order to determine whether we could infer potential MOR-LTD mechanisms from what is known about eCB-LTD, we investigated whether eCB-LTD also occurred at AIC-DLS synapses. We used the same AAV approach described above (Figure supplement $2 \mathrm{~A}$ ) and tested the effects of stimulation- 
135 induced LTD and responses to the CB1 receptor agonist WIN55,212-2 (1 $\mu \mathrm{M})$. We

136 found that eCB-LTD (63 $\pm 7 \%$; Figure 2B-D) and CB1 agonist-induced LTD (68 $\pm 8 \%$;

137 Figure 2B, C, E) both occur at AIC-DLS synapses. Next, we explored the signaling 138 cascades that mediate MOR plasticity in DLS using what is known about eCB-LTD as a 139 guide for our experiments.

140 Inhibition of presynaptic PKA blocks MOR-mediated LTD

141 The activation of opioid receptors produces an inhibition of adenylyl cyclase (AC) 142 mediated by Gai, decreasing cAMP levels, which leads to an attenuation of 143 cAMP/protein kinase A (PKA) signaling(Atwood, Lovinger, et al., 2014). However, little 144 is known about PKA's role in MOR-mediated LTD. Using KT5720 (1 $\mu \mathrm{M})$, a specific and 145 cell permeable inhibitor of PKA, which brain slices were incubated in for $1 \mathrm{~h}$ prior to 146 recordings, we demonstrated that the inhibition of PKA blocks the maintenance of MOR147 LTD of eEPSCs in DLS (101 $\pm 6 \%$; Figure 3A-C). Corticostriatal MOR-LTD was also blocked by PKA inhibition (90 $\pm 5 \%$; Figure $3 G-I)$, as was MOR-LTD at AIC-DLS synapses (96 $\pm 4 \%$; Figure $3 \mathrm{M}-\mathrm{O})$. We found that these effects were due to inhibiting presynaptic PKA activity as at least 30 min treatment with the membrane-impermeable PKA inhibitor PKI $(1 \mu \mathrm{M})$, intracellularly infused through the recording micropipette into 152 the postsynaptic MSN, did not affect MOR-LTD in the DLS (eEPSCs: $84 \pm 2 \%$; Figure 153 3D-F) (corticostriatal oEPSCs: $54 \pm 9 \%$; Figure 3J-L) (AIC-DLS oEPSCs: $62 \pm 6 \%$; 154 Figure 3P-R). Furthermore, thalamostriatal inputs, that express MOR-mediated STD, 155 were not affected by broad inhibition of PKA (15-20 min: $84 \pm 6 \%$; 25-35 min: $107 \pm$ $15610 \%)$ or just inhibition of postsynaptic PKA (15-20 min: $87 \pm 3 \%$; 30-40 min: $111 \pm 9 \%$; 
157 Figure supplement 1C-D). As we expected, our data demonstrate the role of 158 presynaptic PKA uniquely in MOR-LTD.

\section{The activation of adenylyl cyclase disrupts MOR-mediated LTD}

Demonstrating a role for PKA signaling in MOR-LTD implicates adenylyl cyclase (AC) signaling as mediating MOR-LTD. To more specifically test this, we persistently activated $\mathrm{AC}$ using $20 \mu \mathrm{M}$ forskolin throughout recording. In the presence of forskolin, DAMGO produced a transient increase of the EPSC amplitudes (Figure 4B, E and H), followed by a blockade MOR-LTD at all excitatory synapses (105 $\pm 4 \%$; Figure 4A-C) and at corticostriatal (102 $\pm 3 \%$; Figure 4D-F) and AIC inputs (93 \pm 7\%; Figure 4G-I). MOR-mediated STD at thalamic synapses was not affected by the application of

167 forskolin (15-20 min: $83 \pm 6 \%$; 25-35 min: $96 \pm 6 \%$; Figure supplement 1E-F).

168 Altogether, these findings indicate that cAMP/PKA signaling pathway is involved in the induction and maintenance of MOR-LTD in DLS.

170 Protein translation is required to produce MOR-mediated LTD

171 Next, we tested the role of protein translation in MOR-LTD. Using, bath application of 80 $172 \mu \mathrm{M}$ cycloheximide (selective inhibitor of protein synthesis) during the entire recording,

173 we found that the inhibition of protein translation blocked MOR-LTD generally (104 \pm 174 9\%; Figure 5A-C) and specifically at cortical (105 $\pm 9 \%$; Figure 5D-F) and AIC inputs (91 $175 \pm 2 \%$; Figure 5G-I). Similar to our experiments targeting cAMP/PKA signaling, thalamic 176 inputs were unaffected by cycloheximide treatment (15-20 min: $73 \pm 6 \%$; 30-40 min: 98 $177 \pm$ 9\%; Figure supplement 1G-H). 
178 It had been reported that eCB protein translation-mediated-LTD involves mTOR 179 signaling in the hippocampus. To test if mTOR is required for eCB-LTD also in the DLS, 180 we used bath application of $100 \mathrm{nM}$ Torin 2 (a selective mTOR inhibitor). We 181 demonstrated that the inhibition of mTOR signaling disrupted eCB-LTD in the DLS 182 (Control: $77 \pm 3 \%$ vs Torin 2: $103 \pm 8 \%$; Figure 6A-C). However, MOR-LTD does not 183 require $\mathrm{mTOR}$ signaling in the DLS (79 $\pm 2 \%$; Figure 6D-F). These data suggest that 184 protein translation is necessary for MOR-mediated LTD, but mTOR signaling is not 185 involved and indicate that eCB- and MOR-LTD, while qualitatively similar, do not utilize 186 identical signaling mechanisms.

\section{Calcium signaling is not required for MOR-mediated LTD}

188 Our data to this point indicates that presynaptic cAMP/PKA and protein synthesis are 189 critical for the induction and maintenance of MOR-LTD. However, calcium is vital to presynaptic neurotransmitter release and calcium-sensitive signaling mechanisms may

191 be required for LTD induction(Atwood, Lovinger, et al., 2014). Therefore, we next tested 192 whether $\mathrm{Ca}^{2+}$ is critical for MOR-LTD expression. First, we replaced $\mathrm{Ca}^{2+}$ for $\mathrm{Sr}^{2+}$ 193 throughout the duration of the recording, to induce asynchronous glutamate release. We 194 found that the replacement of $\mathrm{Ca}^{2+}$ did not impact MOR-LTD (74 $\pm 5 \%$; Figure 195 supplement 2). Thus, we used another approach where we prepared a DAMGO solution 196 without $\mathrm{Ca}^{2+}$ in order to evaluate the role of $\mathrm{Ca}^{2+}$ in the induction of MOR-LTD. Our data 197 show that $\mathrm{Ca}^{2+}$ is not necessary to induce MOR-LTD (82 $\pm 7 \%$; Figure supplement 2 ).

198 Presynaptic HCN1 channels are indispensable for MOR-mediated LTD

199 Given that we identified cAMP signaling as important for MOR-LTD expression (Figure 200 4), we also explored the possibility of HCN1 channels as key factors for MOR-LTD. To 
201 do so, we applied the general HCN blocker ZD7288 (25 $\mu \mathrm{M})$ to brain slices for at least

20230 minutes before DAMGO application and during the entire recording. HCN inhibition

203 blocked the expression of MOR-LTD (101 $\pm 7 \%$; Figure 7A-C), suggesting a novel role

204 for HCN channels in DLS glutamatergic synaptic plasticity. Next, we characterized the

205 effects of HCN channels in glutamatergic DLS synaptic transmission, by bath applying

$20625 \mu \mathrm{M}$ ZD7288 for at least 15 minutes before recording sEPSCs. We found that the

207 inhibition of HCN channels caused an enhancement in the frequency and a decrease in

208 the amplitude of sEPSCs (Figure 7D-F), without affecting rise and decay times (Figure

$2096 \mathrm{C}, \mathrm{G}$ and $\mathrm{H}$ ). These data suggest, that $\mathrm{HCN}$ channels are present on both pre- and

210 postsynaptic sites and they mediate MOR-LTD in the DLS.

211 To further characterize this new role of HCN channels and establish that presynaptic

212 HCN1 channels are specifically involved in the mechanism of expression of MOR-LTD,

213 we used HCN1flox mice injected with AAV-cre vector into AIC to knock out the

214 expression of HCN1 channel specifically in the AIC, and using AAV-GFP vector-infused

215 mice as controls (Figure 7A, B). Using electrical stimulation and recording in the DLS,

216 we found that the ablation of HCN1 in the AIC reduced the magnitude of MOR-LTD in

217 AAV-cre-injected mice (Figure 7C-F), relative to AAV-GFP-injected mice (Figure 7C-G;

218 cre: $90 \pm 4 \%$ vs GFP: $76 \pm 3 \%$; Figure 7E). Next, we tested if the deletion of presynaptic

219 HCN1 channels produced changes in basal striatal glutamatergic transmission. We

220 found that the lack of AIC HCN1 channels did not affect any synaptic parameters

221 (Figure $7 \mathrm{H}-\mathrm{L})$. These data suggest that HCN1 channels specifically on AIC inputs are

222 necessary for MOR-LTD expression in the DLS. 


\section{Discussion}

225 The current study demonstrates that the mechanism of MOR-mediated LTD is similar to

226 the mechanism of induction of the inhibition of glutamate of CB1 or eCB-LTD in that it 227 involves cAMP-PKA-protein translation signaling and both occur at AIC-DLS synapses

228 (Atwood, Lovinger, et al., 2014; Lonart et al., 2003; Mato, Lafourcade, Robbe, Bakiri, \& Manzoni, 2008; Yasuda, Huang, \& Tsumoto, 2008; Yin et al., 2006; Younts et al., 2016) mTOR signaling and calcium (Figure 6 and supplement 2) and a novel mechanism involving HCN1 signaling for MOR-LTD (Figures 7 and 8). Figure Supplement 3 summarizes the findings of the paper. Furthermore, the MOR-LTD mechanism is different than that of MOR-STD (Figure supplement 1), suggesting that MOR-mediated plasticity does not utilize a common pathway at all glutamatergic synapses. MOR-mediated LTD at glutamate inputs to the DLS(Munoz et al., 2018). However in the DMS, MORs on medial prefrontal cortex, anterior cingulate cortex, and basolateral amygdala inputs are capable of inducing LTD(Muñoz et al., 2020). MOR-LTD also occurs locally at cholinergic interneuron synapses that co-release glutamate on to LTD at AIC inputs to DLS and at medial prefrontal and anterior cingulate cortex inputs to

243 DMS leaving MOR plasticity at thalamostriatal, amygdalostriatal and cholinergic 244 interneurons unaffected(Munoz et al., 2018; Muñoz et al., 2020). We also found that the 245 opioid oxycodone disrupts MOR-LTD in DLS(Atwood, Kupferschmidt, et al., 2014), and 246 given that this is mediated by AIC-DLS MORs(Munoz et al., 2018), it follows that alcohol 
247 and opioids have similar actions on MOR plasticity at this synapse. Given that alcohol

248 (and presumably oxycodone and other opioids) do not affect MOR plasticity at these

249 other non-corticostriatal synapses, differential mechanisms that underlie MOR plasticity

250 at each type of synapse may confer susceptibility to the deleterious effects of these

251 drugs and could account for their mechanisms of action in the development of habitual

252 or compulsive use of the drugs.

253 Previous work has shown that the inhibition of PKA disrupts eCB-LTD in the nucleus

254 accumbens(Mato et al., 2008) and that presynaptic PKA is required to induce

255 cannabinoid LTD in cerebellum(Lonart et al., 2003) and eCB synaptic plasticity in

256 hippocampus(Yasuda et al., 2008). Moreover, previous reports had shown that the

257 activation of AC by forskolin enhances corticostriatal EPSC amplitudes(Cho et al., 2008)

258 and blocked delta opioid receptor-mediated LTD of inhibitory postsynaptic

259 currents(Patton, Roberts, Lovinger, \& Mathur, 2016). cAMP/PKA signaling has also

260 been implicated in type 2/3 metabotropic glutamate receptor- and type $1 \mathrm{~b}$ serotonin

261 receptor-mediated LTD at various synapses in the brain(Atwood, Kupferschmidt, et al.,

262 2014). Until now, the role of cAMP/PKA signaling pathway in MOR-mediated plasticity

263 had not been addressed. Our results demonstrate that presynaptic PKA inhibition

264 blocked AIC-DLS MOR-LTD (Figure 3), but not thalamostriatal MOR-STD (Figure

265 supplement 1C-D). While the magnitudes and time courses differed slightly between

266 measures of eEPSCs and oEPSCs, it appears that PKA is not required for MOR-

267 mediated inhibition of glutamate release, but it is required for the maintenance of MOR-

268 LTD. On the other hand, we found that AC activation disrupted both acute MOR-

269 mediated inhibition (in fact turning it into a transient potentiation) and MOR-LTD (Figure 
4), but had no effect on MOR-STD (Figure supplement 1E-F). Altogether these data suggest that cAMP/PKA pathway may be a general mechanism whereby GPCRs that signal through Gai may induce LTD, but a receptor's ability to couple to Gai does not necessarily mean that it will induce cAMP/PKA-dependent LTD upon activation.

Protein translation is necessary for striatal eCB-LTD(Yin et al., 2006) and is involved in GPCR-mediated LTD at some synapses, but not others(Atwood, Kupferschmidt, et al., 2014; Younts et al., 2016) suggesting that protein translation can be an important

277 component of glutamatergic LTD, depending on the synapse. Indeed, local protein translation can take place in the presynaptic region, where the activation of CB1 receptors enhances protein translation, being critical for the induction and not the maintenance of inhibitory LTD(Younts et al., 2016). Here we demonstrated that protein translation is necessary to produce MOR-LTD (Figure 5), but not MOR-STD (Figure supplement $1 \mathrm{G}-\mathrm{H})$. Our data is consistent with the previous reports on protein translation-dependent eCB-LTD, and suggest that it is presynaptic protein translation

284 that is involved in MOR-LTD expression, however more data is needed to determine 285 this definitively.

Although we have previously reported that MOR- and eCB-LTD are mutually occlusive in the DLS(Atwood, Kupferschmidt, et al., 2014), and here we found that there were similarities between MOR-LTD and eCB-LTD mechanisms, we found some differences which make both types of LTD distinct. In the DLS, MOR-LTD of glutamate input is

290 restricted to those from the AIC(Munoz et al., 2018), which differs from the more broadly 291 expressed (and overlapping at AIC-DLS synapses, Figure supplement 2) eCB-

292 LTD(Gremel et al., 2016; Wu et al., 2015), suggesting that these two forms of LTD may 
293 occur in distinct synaptic environments that could utilize differing mechanisms. It is likely

294 that even in synapses where both receptors are expressed (e.g. in AIC terminals) that

295 each receptor shares partially overlapping, but not identical signaling pathways.

296 A clear example of distinct signaling mechanisms identified here is in the role of the

297 mTOR pathway in eCB-LTD and MOR-LTD. The CB1 receptor can signal via mTOR in

298 the hippocampus, where the increase of protein translation induced by CB1 receptor

299 activation is mTOR-dependent producing inhibitory eCB-LTD(Younts et al., 2016). We

300 predicted that we would see the same effect in the DLS for both eCB-LTD and for MOR-

301 LTD. Partially correct in our prediction, we found that eCB-LTD is blocked after the

302 inhibition of mTOR in the DLS (Figure 6A-C), but the mechanism of MOR-LTD did not

303 utilize mTOR (Figure 6D-F). These novel data regarding eCB-mTOR signaling in DLS

304 provide rationale for future experiments addressing the role of eCB-mTOR signaling in

305 dorsal striatal- related behaviors.

306 Calcium signaling also plays an important role in the mechanism of synaptic 307 plasticity(Frank, Pielage, \& Davis, 2009; Tien \& Kerschensteiner, 2018). Postsynaptic $308 \mathrm{Ca}^{2+}$ influx is needed to produce eCBs (Tanimura et al., 2010), which interacts with 309 presynaptic mechanism to produce LTD(Adermark, 2011; Adermark, Talani, \& Lovinger,

310 2009; Cristiano Nazzaro et al., 2012; Plotkin et al., 2013; Wang et al., 2006). Some 311 forms of GPCR-mediated LTD, including eCB-LTD, also require presynaptic calcium 312 signaling as well(Atwood, Lovinger, et al., 2014). However, we demonstrated that $\mathrm{Ca}^{2+}$ 313 is not involved in MOR-LTD in DLS (Figure supplement 2), indicating another difference 314 between the mechanisms of MOR-LTD and eCB-LTD. 
315 Presynaptic cations such as $\mathrm{Na}^{+}$and $\mathrm{K}^{+}$are important for the propagation of action potentials and subsequent glutamate release(Chen \& Lui, 2021). HCNs channels are

317 permeable to $\mathrm{Na}^{+}$and $\mathrm{K}^{+}$and modulated by cAMP(Sartiani, Mannaioni, Masi, Novella

318 Romanelli, \& Cerbai, 2017), and they can decrease neurotransmission by restricting 319 presynaptic $\mathrm{Ca}^{2+}$ influx(Zhuo Huang et al., 2011). However, while we did not find that

$320 \mathrm{Ca}^{2+}$ plays a role in MOR-LTD, we did identify a critical role for the HCN1 channel in 321 MOR-LTD expression (Figures 7 and 8). It has been reported that HCN1 channels can

322 be found at presynaptic sites in the globus pallidus, where the inhibition by ZD7288 323 produced an increase of miniature inhibitory postsynaptic current frequency, with no 324 changes in amplitude(Boyes, Bolam, Shigemoto, \& Stanford, 2007). The block or

325 deletion of HCN1 causes an increase in the frequency of miniature EPSCs in entorhinal 326 cortical pyramidal neurons(Zhuo Huang et al., 2011). Here we showed that broad

327 blockade of HCN channels enhanced glutamate release, but decreased postsynaptic 328 responses to glutamate (Figure 7D-H), presumably by acting non-specifically at both 329 presynaptic and postsynaptic sites. However, when we deleted just HCN1 from AIC 330 inputs to DLS, we did not observe any changes in basal glutamate transmission (Figure $3318 \mathrm{H}-\mathrm{L})$. The differences in effects of broad blockade and synapse-specific deletion may 332 be attributed to the overall contribution of HCN1s at AIC inputs relative to the population 333 of glutamate synapses. Genetic deletion did not completely ablate MOR-LTD 334 expression. This could be due to an incomplete AAV vector transduction (most 335 recordings had a complete loss of LTD) or perhaps that HCN1 contributes to LTD 336 differently at AIC inputs to different subtypes of MSNs. Therefore, in the future, it will 337 also be important to investigate the role of HCN1 in MOR-LTD at AIC inputs to D1- or 
D2-expressing MSNs (direct or indirect pathway respectively). It has recently been

339 reported that HCN1 contributes to alcohol preference(Salling \& Harrison, 2020). Given

340 that alcohol disrupts MOR-LTD in DLS, this mechanism of MOR-HCN1 signaling may

341 be a target of alcohol's effects and contribute to alcohol-related, dorsal striatal-

342 dependent behaviors such as habitual and compulsive alcohol drinking. As the opioid

343 oxycodone also disrupts MOR-LTD it will be intriguing to determine the impact of both

344 oxycodone and alcohol on AIC-DLS HCN1 function. HCN1 may therefore have

345 therapeutic potential in alcohol and opioid use disorders.

346 In conclusion, these findings indicate that glutamatergic synapses in the DLS have

347 distinct mechanisms of plasticity induction mediated by the same types of receptors.

348 The specific signaling processes that result in these different forms of plasticity might be

349 the answer to why different types of plasticity are differentially sensitive to drugs of 350 abuse and alcohol(Atwood, Lovinger, et al., 2014; Munoz et al., 2018; Muñoz et al., 351 2020). However, further work is required to resolve what components of these

352 mechanisms render some synapses susceptible to the deleterious effects of these 353 drugs while others are resistant. It will also be important to decipher the behavioral 354 relevance of AIC-DLS synapse HCN1 channels and eCB-mTOR signaling in the DLS. 


\section{Methods}

\section{Methods details}

358 All experiments were performed similar to our previous dorsal striatal 359 electrophysiological studies with some experiment-specific modifications(Atwood, 360 Kupferschmidt, et al., 2014; Fritz, Munoz, \& Atwood, 2019; Fritz, Munoz, Yin, Bauchle, 361 \& Atwood, 2018; Munoz et al., 2018). These methods are described in brief below.

\section{Animals and materials}

Animal care and experimental protocols for this study were approved by the Institutional Animal Care and Use Committee (IACUC) at the Indiana University School of Medicine and all guidelines for ethical protocols and care of experimental animals established by the NIH (National Institutes of Health, Maryland, USA) were followed. Male C57BL/6J

367 mice were obtained from the Jackson Laboratory (JAX \#000664, Bar Harbor, Maine, 368 USA). Emx1Cre-Ai32, VGluT2Cre-Ai32, and HCN1fox mice were bred and genotyped in369 house (Original stock strains: Ai32: JAX \#012569; Emx1Cre: JAX \#005628; VGluT2Cre: 370 JAX \#016963; HCN1f/f: JAX \#028299). All mutant mice used in these studies were 371 backcrossed to C57BL/6J mice for a minimum of 7 generations. The mice used in these 372 studies were between PND 60-100 at the time of experimentation (with the exception of

373 HCN1-flox AAV-cre-injected mice PND 98-154). Animals were group-housed in a 374 standard 12-h light/dark cycle (lights on at 0800 ) at $50 \%$ humidity. Food and water were 375 available ad libitum.

\section{Reagents}

377 We used the MOR agonist [D-Ala ${ }^{2}, \mathrm{NMe}-\mathrm{Phe}^{4}, \mathrm{Gly}^{-o l^{5}}$ ]-enkephalin (DAMGO; H-2535, 
378 Bachem), GABA $A_{A}$ receptor antagonist picrotoxin (PTX, P1675, Sigma-Aldrich), PKI 379 (6221, Tocris), KT5720 (1288, Tocris), Forskolin (F3917, Sigma-Aldrich), Cycloheximide (0970, Tocris), ZD7288 (1000, Tocris), WIN55,212-2 (1038, Tocris), and Torin 2 (4248,

381 Tocris). Other reagents used for making solutions were purchased from Sigma-Aldrich or 382 Fisher Scientific.

\section{Brain slice preparation.}

384 Mice were euthanized via decapitation under deep isoflurane anesthesia, and the brain 385 was quickly excised and placed in an ice-cold cutting solution containing (in mM): 194 sucrose, $30 \mathrm{NaCl}, 4.5 \mathrm{KCl}, 1 \mathrm{MgCl}_{2}, 26 \mathrm{NaHCO}_{3}, 1.2 \mathrm{NaH}_{2} \mathrm{PO}_{4}, 10$ Glucose saturated with a mixture of $95 \% \mathrm{O}_{2}$ and $5 \% \mathrm{CO}_{2}$, and sliced to a thickness of $280 \mu \mathrm{m}$ on a vibratome (Leica VT1200S, Germany). Slices were transferred to an artificial cerebrospinal fluid (aCSF) solution containing (in mM): $124 \mathrm{NaCl}, 4.5 \mathrm{KCl}, 1 \mathrm{MgCl}_{2}, 26$ $\mathrm{NaHCO}_{3}, 1.2 \mathrm{NaH}_{2} \mathrm{PO}_{4}, 10$ Glucose, $2 \mathrm{CaCl}_{2}$ (310-320 mOsm) saturated with 95\% $\mathrm{O}_{2} / 5 \% \mathrm{CO}_{2}$ at $30^{\circ} \mathrm{C}$ for $1 \mathrm{hr}$ before being moved to room temperature. When ready for recording, slices were transferred to a recording chamber continuously perfused with aCSF solution saturated with $95 \% \mathrm{O}_{2} / 5 \% \mathrm{CO}_{2}$.

\section{Electrophysiology recordings}

395 Whole-cell recordings of excitatory postsynaptic currents (EPSCs) in medium spiny 396 neurons (MSNs) were carried out at 29-32 $\mathrm{C}^{\circ}$ and aCSF was continuously perfused at a 397 rate of $1-2 \mathrm{ml} / \mathrm{min}$. Recordings were performed in the voltage clamp configuration using a 398 Multiclamp 700B amplifier and a Digidata 1550B (Molecular Devices, San Jose, CA). 399 Slices were visualized on an Olympus BX51WI microscope (Olympus Corporation of 
400 America). MSNs were identified by their size, membrane resistance, and capacitance.

401 Picrotoxin $(50 \mu \mathrm{M})$ was added to the aCSF for recordings to isolate excitatory

402 transmission. Patch pipettes were prepared from filament-containing borosilicate

403 micropipettes (World Precision Instruments) using a P-1000 micropipette puller (Sutter

404 Instruments, Novato, CA), having a 2.0-3.5 $\mathrm{M} \Omega$ resistance. The internal solution

405 contained (in mM): $120 \mathrm{CsMeSO}_{3}, 5 \mathrm{NaCl}, 10 \mathrm{TEA}-\mathrm{Cl}, 10 \mathrm{HEPES}, 5$ lidocaine bromide,

406 1.1 EGTA, 0.3 Na-GTP and 4 Mg-ATP (pH 7.2 and 290-310 mOsm). MSNs were voltage

407 clamped at $-60 \mathrm{mV}$ for the duration of the recordings. To evaluate the effect of $\mathrm{Ca}^{2+}$,

408 aCSF $\mathrm{Ca}^{2+}$ was replaced with $\mathrm{Sr}^{2+}(2 \mathrm{mM})$ during the application of DAMGO (from 10 to

$40915 \mathrm{~min}$ after the start of recording) or through the entire recording (from 0 to $40 \mathrm{~min}$ ). For

410 electrically-evoked recordings, a twisted tungsten bipolar stimulating electrode

411 (PlasticsONE, Roanoke, VA) was placed at the border of the white matter of the external

412 capsule. Electrically-evoked excitatory postsynaptic currents (eEPSCs) were generated

413 by a DS3 Isolated Current Stimulator (Digitimer, Ft. Lauderdale, FL) every $20 \mathrm{~s}$ and

414 stimulus intensity was adjusted to produce stable eEPSCs of 200-600 pA in amplitude

415 prior to the initiation of experimental recording. The spontaneous EPSC (sEPSC)

416 recordings were made for 2 min and the analysis of frequency $(\mathrm{Hz})$, decay constant (ms),

417 rise constant (ms) and amplitude (pA) were measured to determine the effects of the

418 deletion of HCN1 in AIC. The decay constant of sEPSCs was fitted as single exponential

419 and both rise and decay-phase were fitted between 10 and $90 \%$ of the maximal

420 amplitude. Data were acquired using Clampex 10.3 (Molecular Devices, San Jose, CA).

421 Series resistance was monitored and only cells with a stable series resistance (less than

$42225 \mathrm{M} \Omega$ and that did not change more than $15 \%$ during recording) were included for data 
423 analysis. Recordings were made $2-7 \mathrm{~h}$ after euthanasia.

$424 \quad$ Viral injections

425 C57BL/6J mice were anesthetized with isoflurane and stereotaxically-injected with the 426 adeno-associated viral (AAV) vector, AAV9.hSyn.ChR2(H134R)-eYFP (Addgene 427 \#26973) to drive ChR2 expression in AIC neurons. Bilateral injections were made into 428 AIC: A/P: +2.4, M/L: $\pm 2.3, \mathrm{D} / \mathrm{V}:-2.25$ (50 nl/injection, $12.5 \mathrm{nl} / \mathrm{min}$ infusion rate).

429 To produce AIC projection neuron HCN1 knockout mice, HCN1-flox mice were anesthetized with isoflurane and stereotaxically-injected

with

433 made into $\mathrm{AIC}$ at coordinates: A/P: +2.4, M/L: $\pm 2.3, \mathrm{D} / \mathrm{V}:-2.25$ (75 nl/injection, 12.5 $434 \mathrm{nl} / \mathrm{min}$ infusion rate). HCN1-flox mice were allowed to recover for at least 4 weeks to

435 allow for adequate ablation of HCN1 channel expression before brain slices were made 436 for electrophysiological recordings. Prior to recording, brain slices were imaged via an

437 Olympus MVX10 microscope (Olympus Corporation of America) to verify GFP or GFP. 438 tagged cre-recombinase expression in injected HCN1flox mice.

\section{Optogenetic Recordings}

AAV-ChR2 injection in C57BL/6J mice was performed to target ChR2 expression to

441 inputs from AIC to DLS. Optically-evoked EPSCs (oEPSCs) in MSNs from Emx1-Ai32, 442 VGluT2-Ai32 and C57BL/6J mice injected with AAV-ChR2 were produced in brain slices 443 using 470-nm blue light (5-ms exposure time) delivered via field illumination through the 444 microscope objective. Light intensity was adjusted to produce stable oEPSCs of 200- 
445 600-pA amplitude prior to experimental recording. oEPSCs were evoked every 30s. AIC-

446 DLS eCB-LTD was produced using optical high-frequency stimulation (oHFS) coupled

447 with depolarization (4 blue light pulses of $50 \square \mathrm{Hz}, 10 \square \mathrm{s}$ inter-pulse interval). Prior to 448 recording, brain slices were imaged via an Olympus MVX10 microscope (Olympus

449 Corporation of America) to verify YFP-tagged ChR2, GFP-tagged cre-recombinase, or 450 GFP expression in injected C57BL/6J mice.

\section{Quantification and statistical analysis}

\section{Sample size}

453 The target number of samples in each group for electrophysiological experiments was

454 determined from our previously published studies(Atwood, Kupferschmidt, et al., 2014;

455 Munoz et al., 2018; Muñoz et al., 2020).

456

\section{Replication}

457 All sample sizes indicated in figures for electrophysiological experiments represent

458 biological replicates. 1 neuron was recorded per brain slice and all experiments involved 459 recordings from at least 2 mice.

\section{Data analyses}

461 eEPSCs and oEPSCs were analyzed using Clampfit 10.1 (Molecular Devices, San 462 Jose, CA) and sEPSCs with MiniAnalysis 6.0 (Synaptosoft Inc). Unless otherwise 463 indicated, data are presented as the mean \pm SEM. The analyses of normally distributed 464 data were performed using two-tailed unpaired or two-tailed paired Student's t tests 465 following an $\mathrm{F}$ test to confirm similar variances. Non-normally distributed data were 
466 analyzed using two-tailed Welch's t test for unpaired data (Figure 7J-L). Data that were

467 analyzed using this test are indicated in the figure legends. Statistical analyses were

468 performed with Prism 9 (GraphPad, La Jolla, CA). The level of significance was set at $P$

$469<0.05$ for all analyses. Representative traces are the average baseline EPSC (1-10

$470 \mathrm{~min}$ ) and average post-treatment EPSC of final $10 \mathrm{~min}$ of recording. For VGluT2-Ai32

471 recordings, representative traces are the average baseline EPSC (1-10 min) average of

472 the peak of response after DAMGO (15-20 min) and average post-treatment EPSC of

473 final 10 min of recording Exclusion of individual data points was determined using a

474 ROUT outlier calculator $(\mathrm{Q}=1 \%)$ included in the Prism 9 software package. 
476 Acknowledgments: The authors thank Fuqin Yin for expert technical assistance. All

477 reagents and other materials used for this work are commercially available. This work

478 was supported by NIH/NIAAA grant R01 AA027214.

479 Competing interests: The authors declare no conflict of interest. 

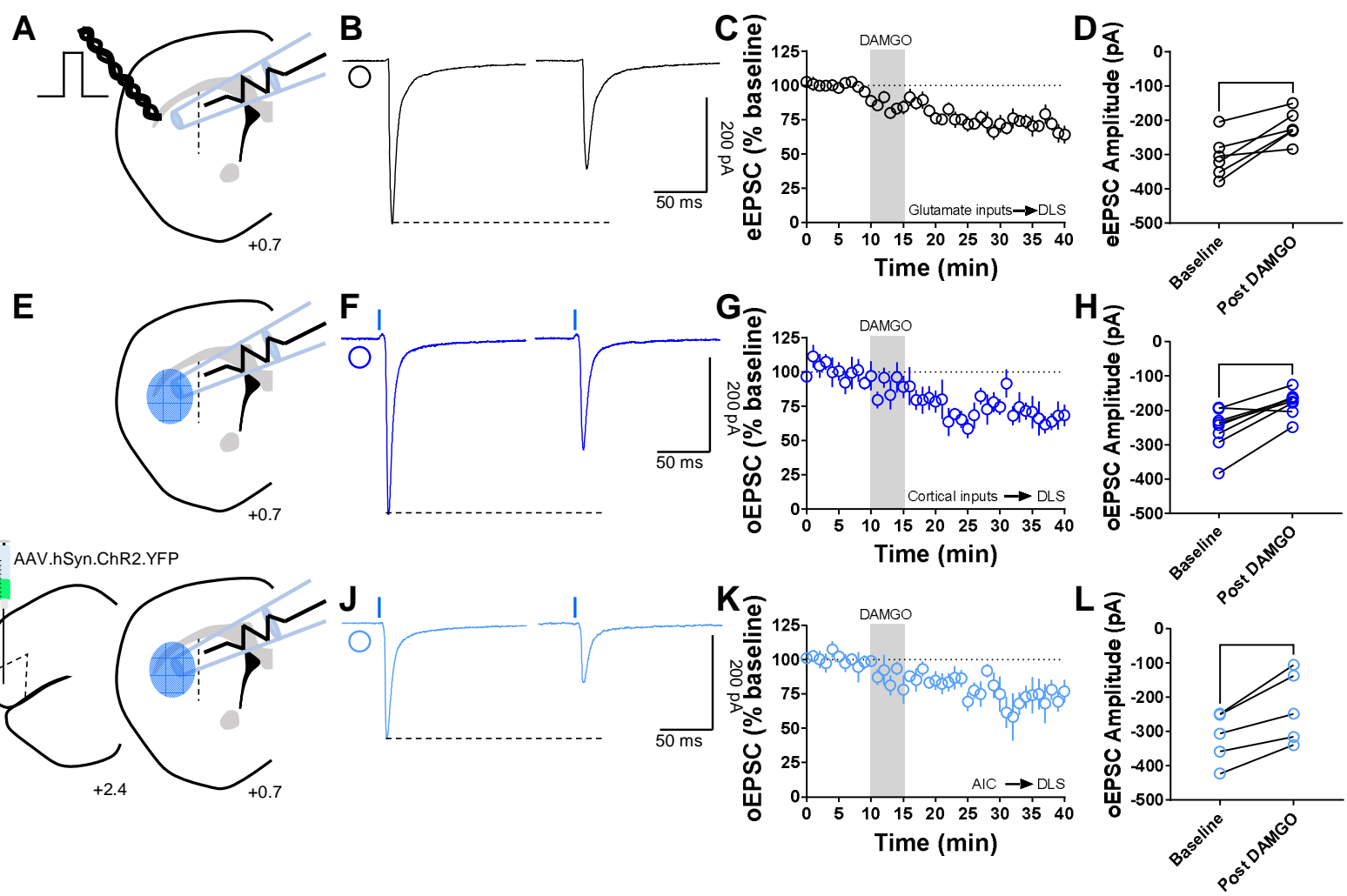

Figure 1. MOR activation induces glutamatergic LTD in the DLS. A) Schematic representation of coronal brain slice showing the recording of EPSCs evoked by focal electric stimulation in the DLS of C57BL/6J mice. B) Representative electrically-evoked EPSC traces before and after DAMGO $(0.3 \square \mu \mathrm{M}, 5 \square \mathrm{min})$ application. C) The activation of MOR by DAMGO induced glutamatergic LTD in DLS MSNs of C57BL/6J (final $10 \square$ min of recording average: $72 \pm 5 \%$ ). D) eEPSC amplitudes in MSNs within DLS were significantly reduced after DAMGO application $(0-10 \square \mathrm{min}$ baseline $\mathrm{v}$. final $10 \square$ min of recording; paired t-test, $\mathrm{P} \square=\square 0.0091, \mathrm{t} 5 \square=4.125, \mathrm{n} \square=\square 6$ neurons from 2 mice). E) Schematic representation of coronal brain slice showing the recording of EPSCs evoked by focal optical stimulation (470-nm blue light for 5-ms exposure) in the DLS of Emx1-Ai32 mice. F) Representative optically-evoked EPSC traces before and after DAMGO $(0.3 \square \mu \mathrm{M}, 5 \square \mathrm{min})$ application. G) The activation of MOR by DAMGO induced corticostriatal LTD in DLS MSNs of Emx1-Ai32 (final 10 $\square \mathrm{min}$ of recording average: $71 \pm 5 \%$ ). H) oEPSC amplitudes were significantly reduced after DAMGO application (0-10 $\square$ min baseline v. final $10 \square$ min of recording; paired t-test, $\mathrm{P} \square=\square 0.0017$, $\mathrm{t} 7 \square=4.9, \mathrm{n} \square=\square 8$ neurons from 3 mice). I) Schematic figure of the injection paradigm showing an AAV vector encoding for ChR2 (AAV.hSyn.ChR2.YFP) in AIC in C57BL/6J mice, this AAV was injected 2 weeks prior to recordings. Also, the next schematic representation of coronal brain slice shows the recording of oEPSCs (470-nm blue light for 5-ms exposure) in the DLS. J) Representative AIC-DLS oEPSC traces before and after DAMGO (0.3 $\square \mu \mathrm{M}, 5 \square \mathrm{min})$ application. K) DAMGO induced AIC-DLS LTD (final $10 \square$ min of recording average: $66 \pm 7 \%$ ). L) DAMGO application significantly reduced 
bioRxiv preprint doi: https://doi.org/10.1101/2021.08 31.458358; this version posted September 1, 2021. The copyright holder for this preprint (which was not certified by peer review) is the author/funder, who has granted bioRxiv a license to display the preprint in perpetuity. It is made available under aCC-BY-NC 4.0 International license.

505 oEPSC amplitudes $(0-10 \square \min$ baseline v. final $10 \square$ min of recording; paired t-test, $506 \mathrm{P} \square=\square 0.0084, \mathrm{t} 4 \square=4.84, \mathrm{n} \square=\square 5$ neurons from 2 mice). Data represent mean \pm SEM. $507 \quad{ }^{\star \star} \mathrm{P} \square<\square 0.01$. 

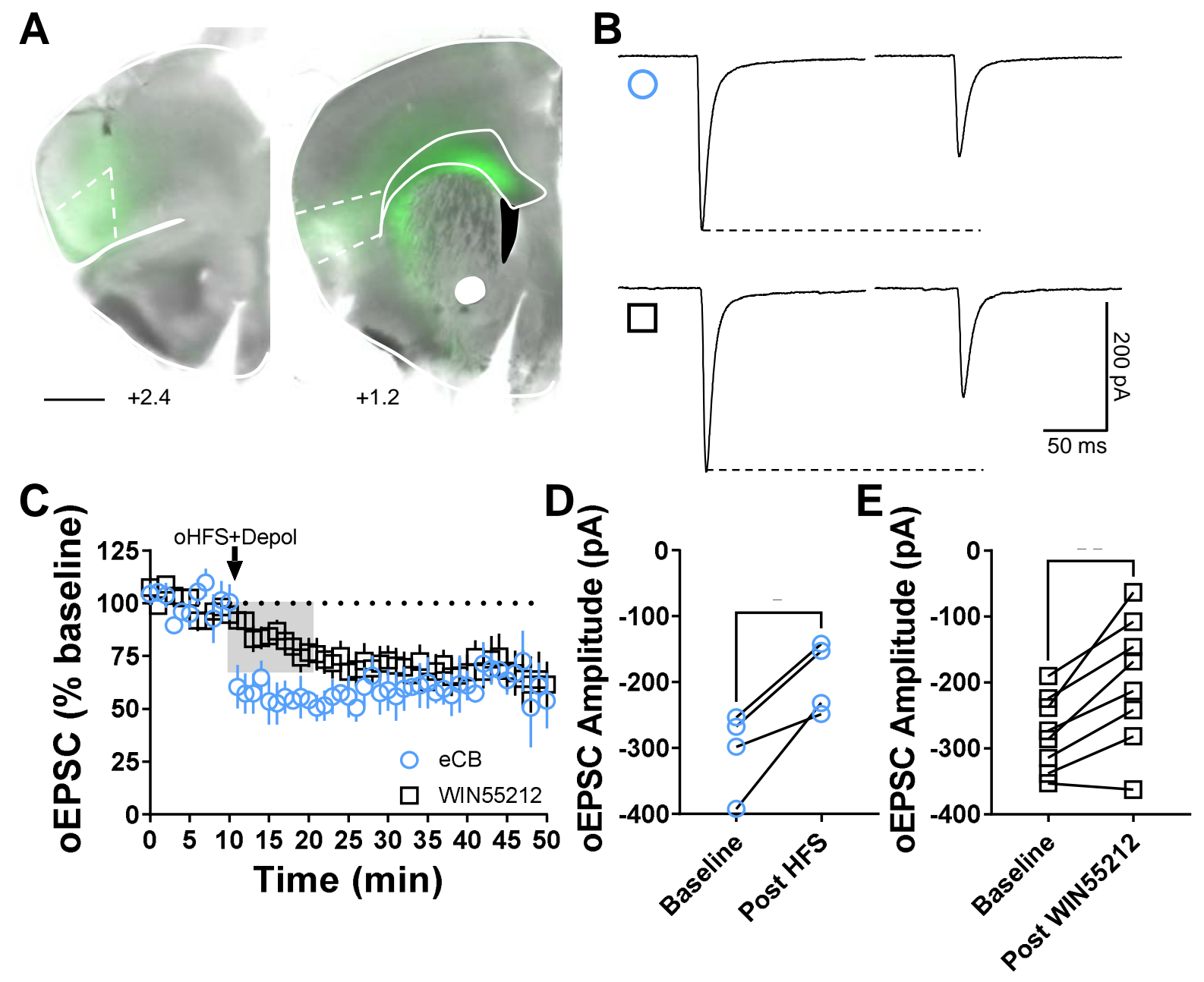

Figure 2. Cannabinoid LTD occurs at AIC-DLS synapses. (A) Coronal brain slice showing the AAV-ChR2 infection of AIC and dorsal striatal terminal expression (bar scale $\square=\square 1000 \square \mu \mathrm{m}$ ). (B) Representative oEPSC traces showing the effects of pairing optical high frequency stimulation with postsynaptic depression (oHFS) or WIN55,212-2 $(1 \square \mu \mathrm{M}, 10 \square \mathrm{min})$ application in brain slices of AAV-ChR2 C57BI/6J mice. (C) Both oHFS and WIN55,212-2 induced AIC-DLS LTD (final 10 $\square$ min of recording average: oHFS: 63 $\pm 7 \%$; WIN55,212-2: $68 \pm 8 \%$ ). (D) oHFS significantly reduced oEPSC amplitudes (0$10 \square$ min baseline v. final $10 \square$ min of recording; paired t-test, $P \square=\square 0.017$, t3 $=4.78$,

$518 \mathrm{n} \square=\square 4$ neurons from 2 mice). E) WIN55,212-2 significantly reduced oEPSC amplitudes $519 \quad(0-10 \square$ min baseline v. final $10 \square$ min of recording; paired t-test, $P \square=\square 0.0038, t 7=4.24$, $520 \mathrm{n} \square=\square 8$ neurons from 4 mice). Data represent mean \pm SEM. ${ }^{*} \mathrm{P} \square<\square 0.05,{ }^{* *} \mathrm{P} \square<\square 0.01$. 

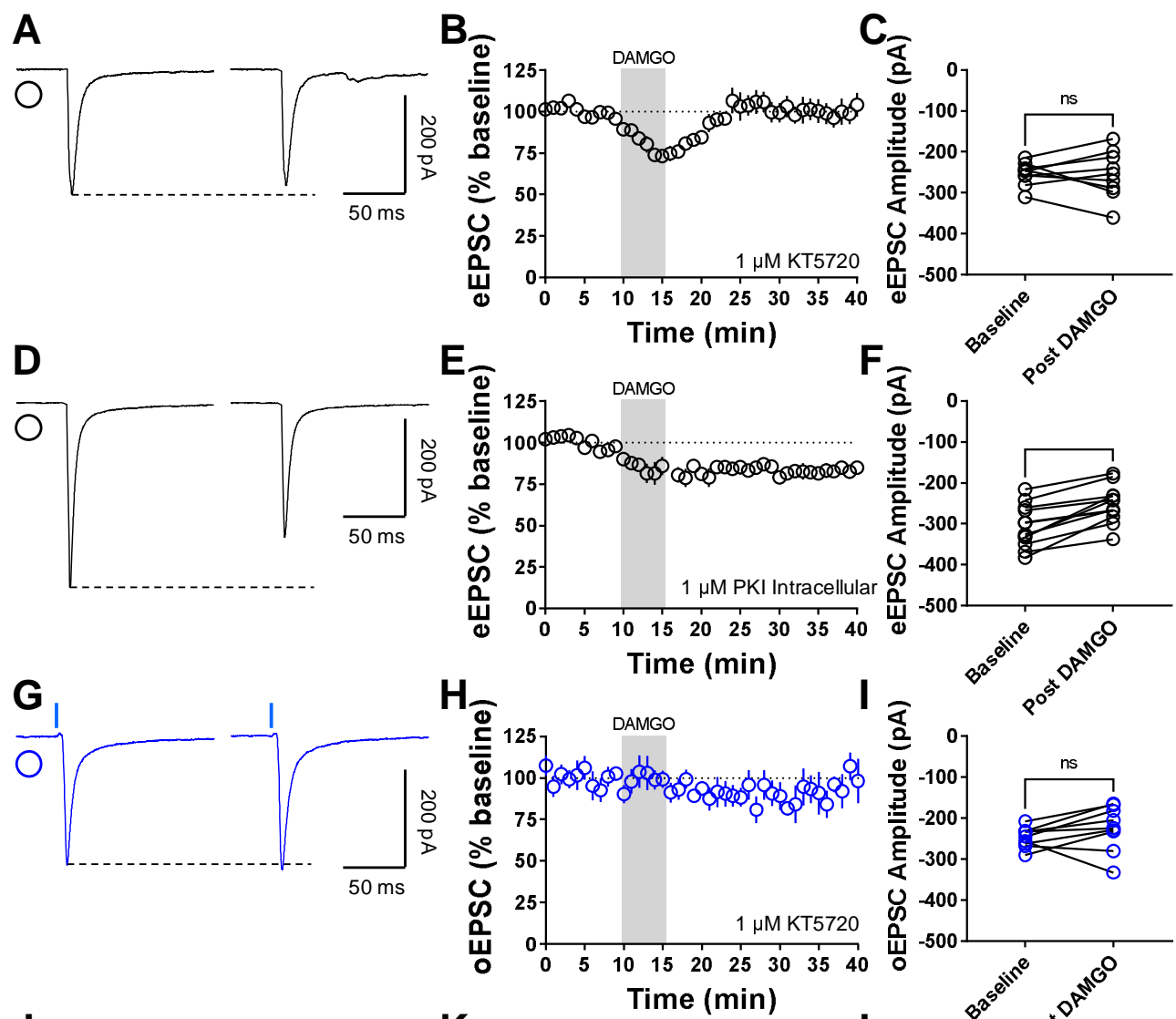
Time (min)
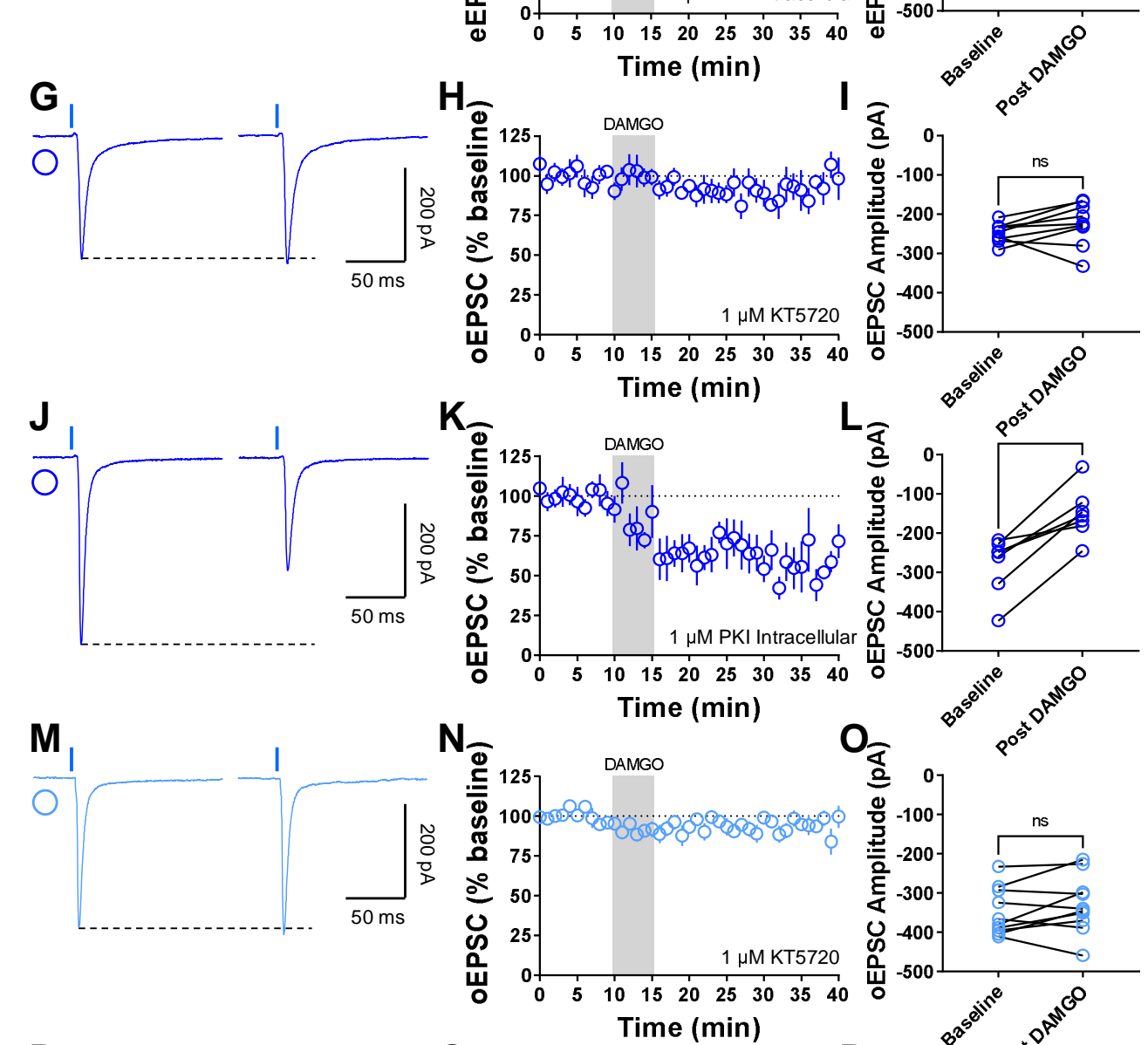

Time (min)
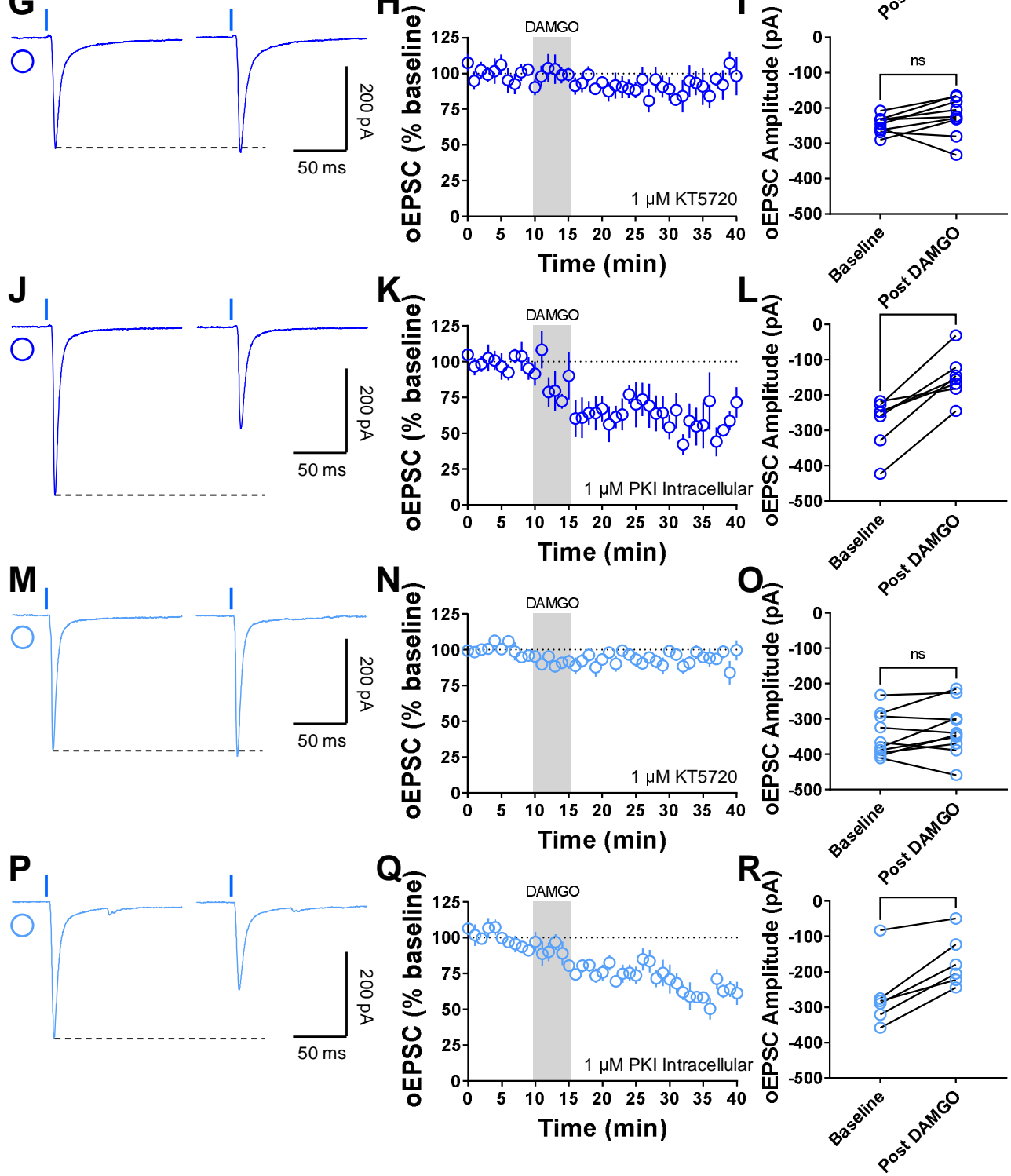
Figure 3. Inhibition of Presynaptic PKA blocks MOR-mediated LTD. (A) Representative eEPSC traces showing the effects of DAMGO $(0.3 \square \mu \mathrm{M}, 5 \square \mathrm{min})$ application after the preincubation of PKA-selective inhibitor, KT5720 (1 $\mu \mathrm{M}, \geq 1 \mathrm{hr})$. (BC) The preincubation of KT5720 blocked glutamatergic MOR-LTD $(101 \pm 6 \%)$, the eEPSC amplitudes did not change after DAMGO application (0-10 $\square$ min baseline v. final $10 \square$ min of recording; paired t-test, $\mathrm{P} \square=\square 0.9487$, t8 $\square=0.0664, \mathrm{n} \square=9$ neurons from 3 mice). (D) Representative eEPSC traces showing the effects of DAMGO $(0.3 \square \mu \mathrm{M}$, $5 \square \mathrm{min})$ application after the intracellular dialysis of PKI $(1 \mu \mathrm{M}, \geq 30 \mathrm{~min})$. (E-F) The inhibition of postsynaptic PKA did not alter MOR-LTD (84 $\pm 2 \%$ ). eEPSC amplitudes were reduced after DAMGO application $(0-10 \square \mathrm{min}$ baseline v. final $10 \square \mathrm{min}$ of recording; paired t-test, $\mathrm{P} \square<\square 0.0001$, $\mathrm{t} 11 \square=6.374, \mathrm{n} \square=12$ neurons from 5 mice). (G) Representative oEPSC traces showing the effects of DAMGO $(0.3 \square \mu \mathrm{M}, 5 \square \mathrm{min})$ application after the preincubation of PKA-selective inhibitor, KT5720 $(1 \mu \mathrm{M}, \geq 1 \mathrm{hr})$. (HI) PKA inhibition blocked corticostriatal MOR-LTD $(90 \pm 5 \%)$, with no changes in oEPSC amplitudes after DAMGO application (0-10 $\square$ min baseline v. final $10 \square$ min of recording; paired t-test, $\mathrm{P} \square=\square 0.162$, t8 $\square=1.541, \mathrm{n} \square=9$ neurons from 4 mice). (J) Representative oEPSC traces showing the effects of DAMGO $(0.3 \square \mu \mathrm{M}, 5 \square \mathrm{min})$ application after the intracellular dialysis of PKI ( $1 \mu \mathrm{M}, \geq 30 \mathrm{~min})$. (K-L) The inhibition of postsynaptic PKA did not alter MOR-LTD (54 \pm 9\%). oEPSC amplitudes were reduced after DAMGO application (0-10 $\square$ min baseline v. final $10 \square \mathrm{min}$ of recording; paired t-test, $\mathrm{P} \square=\square 0.0014$, t6 $\square=5.588, \mathrm{n} \square=7$ neurons from 2 mice). (M) Representative AIC-DLS oEPSC traces showing the effects of DAMGO $(0.3 \square \mu \mathrm{M}, 5 \square \mathrm{min})$ application after the preincubation of PKA-selective inhibitor, KT5720 (1 $\mu \mathrm{M}, \geq 1 \mathrm{hr}$ ). (N-O) KT5720 blocked corticostriatal MOR-LTD (96 $\pm 4 \%)$, with no changes in oEPSC amplitudes after DAMGO application (0-10 $\square$ min baseline v. final $10 \square \mathrm{min}$ of recording; paired t-test, $\mathrm{P} \square=\square 0.2121$, t9 $\square=1.343, \mathrm{n} \square=10$ neurons from 3 mice). (P) Representative AIC-DLS oEPSC traces showing the effects of DAMGO $(0.3 \square \mu \mathrm{M}, 5 \square \mathrm{min})$ application after the intracellular dialysis of PKI ( $1 \mu \mathrm{M}, \geq 30 \mathrm{~min})$. (Q-R) Postsynaptic PKA inhibition did not alter specific AIC MOR-mediated LTD (62 $\pm 6 \%)$. oEPSC amplitudes were reduced after DAMGO application (0-10 $\square$ min baseline v. final $10 \square \mathrm{min}$ of recording; paired t-test, $\mathrm{P} \square=\square 0.0026$, $\mathrm{t} 5 \square=5.576, \mathrm{n} \square=6$ neurons from 3 mice). Data represent mean \pm SEM. ns= no significant, ${ }^{* *} \mathrm{P} \square<\square 0.01,{ }^{* * *} \mathrm{P} \square<\square 0.001,{ }^{* * *} \mathrm{P} \square<\square 0.0001$. 

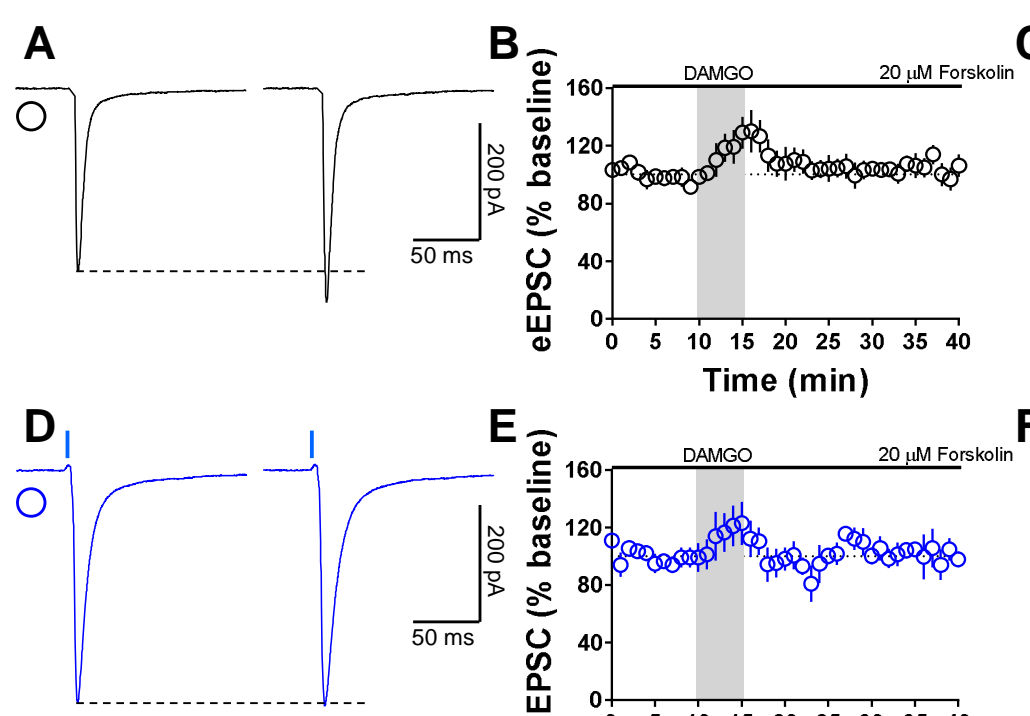

Time (min)
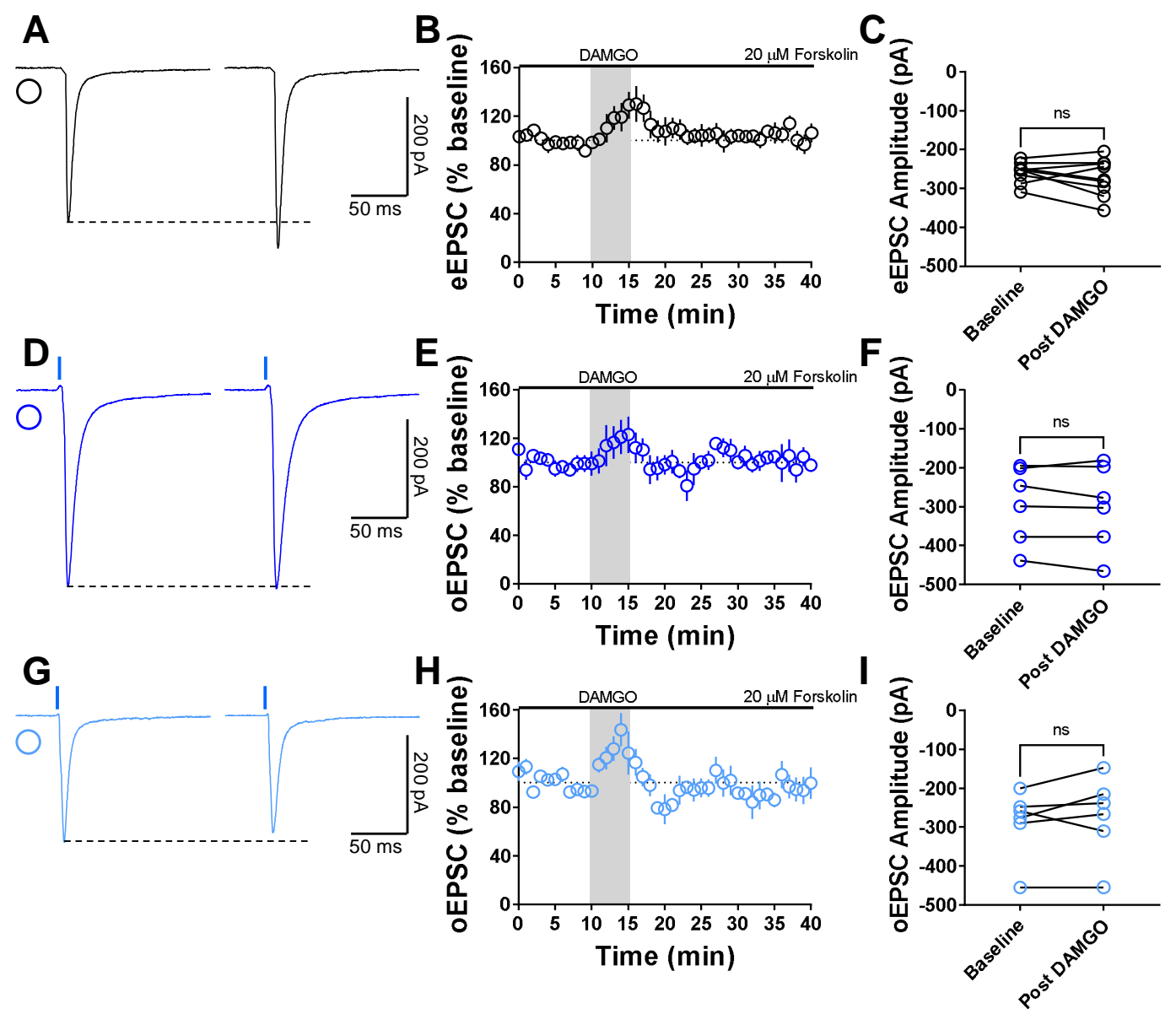

Figure 4. The activation of adenylyl cyclase disrupts MOR-mediated LTD. (A) Representative eEPSC traces showing the effects of $20 \mu \mathrm{M}$ forskolin before, during and after DAMGO $(0.3 \square \mu \mathrm{M}, 5 \square \mathrm{min})$ application. (B-C) AC activation disrupted glutamatergic MOR-LTD (105 $\pm 4 \%)$, showing no changes in eEPSC amplitude after DAMGO bath application (0-10 $\square$ min baseline v. final $10 \square$ min of recording; paired t-test, $\mathrm{P} \square=\square 0.2681$, t8 $\square=1.19, \mathrm{n} \square=9$ neurons from 4 mice). (D) Representative oEPSC traces showing the effects of $20 \mu \mathrm{M}$ forskolin before, during and after DAMGO $(0.3 \square \mu \mathrm{M}, 5 \square \mathrm{min})$ application in brain slices from Emx1-Ai32 mice. (E-F) AC activation disrupted corticostriatal MORLTD (102 $\pm 3 \%$ ), with no effects in oEPSC amplitude after DAMGO bath application (0$10 \square$ min baseline v. final $10 \square$ min of recording; paired t-test, $\mathrm{P} \square=\square 0.4031$, t5 $\square=0.913$, $\mathrm{n} \square=6$ neurons from 3 mice). (G) Representative AIC-DLS oEPSC traces showing the effects of $20 \mu \mathrm{M}$ forskolin before, during and after DAMGO $(0.3 \square \mu \mathrm{M}, 5 \square \min )$ application. (H-I) AC activation blocked specifically AIC MOR-LTD (105 $\pm 4 \%)$, without changes in oEPSC amplitude after DAMGO bath application $(0-10 \square \min$ baseline $\mathrm{v}$. final $10 \square$ min of recording; paired t-test, $\mathrm{P} \square=\square 0.379$, $\mathrm{t} 5 \square=0.964, \mathrm{n} \square=6$ neurons from 2 mice). Data represent mean \pm SEM. $n s=$ no significant. 

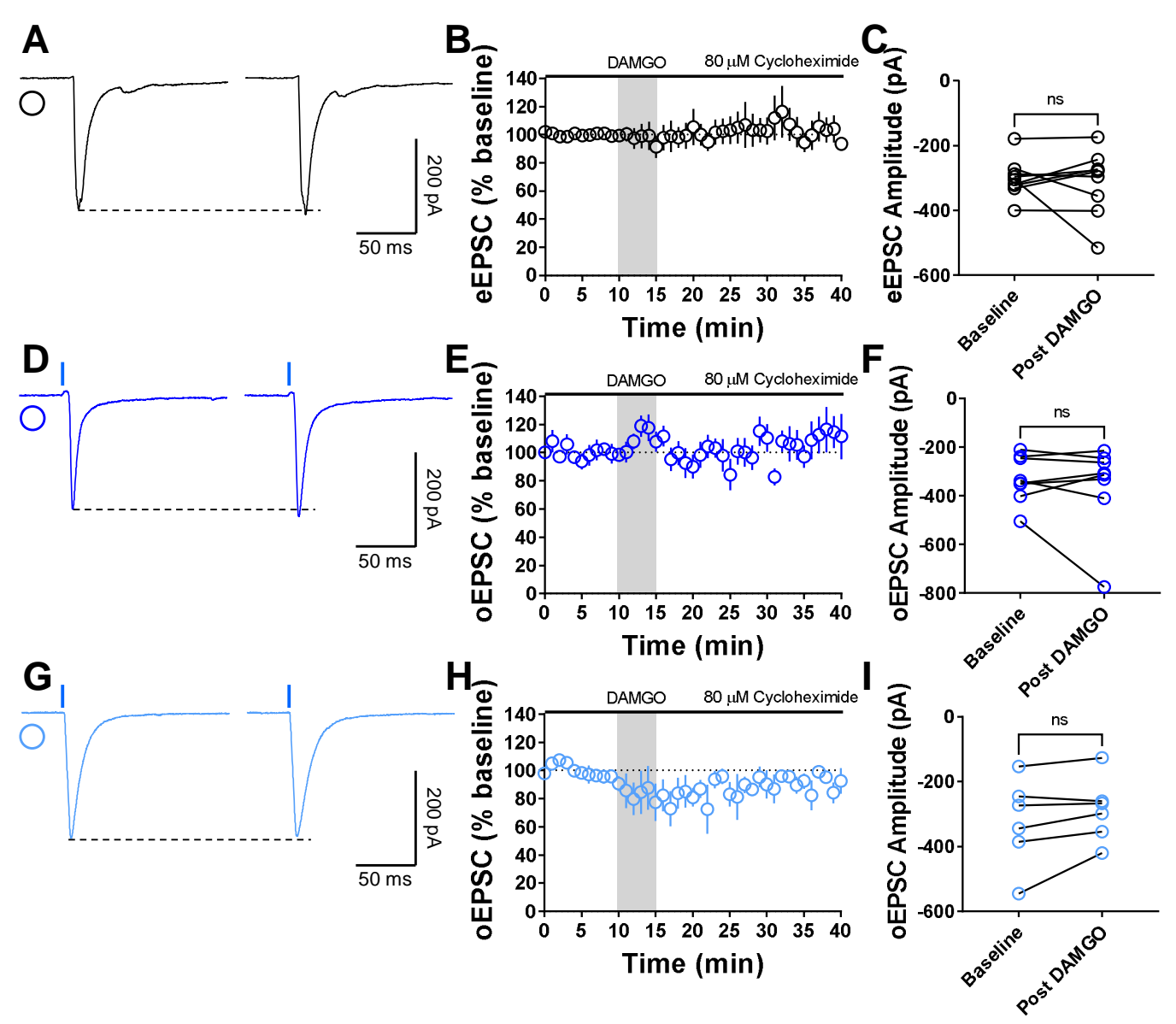
Representative eEPSC traces showing the effects of $80 \mu \mathrm{M}$ cycloheximide before, during and after DAMGO $(0.3 \square \mu \mathrm{M}, 5 \square \mathrm{min})$ application. (B-C) Protein translation inhibition disrupted glutamatergic MOR-LTD (104 $\pm 9 \%)$, showing no changes in eEPSC amplitude after DAMGO bath application $(0-10 \square \mathrm{min}$ baseline $\mathrm{v}$. final $10 \square \mathrm{min}$ of recording; paired t-test, $\mathrm{P} \square=\square 0.7006$, t $\square \square=0.398, \mathrm{n} \square=9$ neurons from 4 mice). (D) Representative oEPSC traces showing the effects of $80 \mu \mathrm{M}$ cycloheximide before, during and after DAMGO $(0.3 \square \mu \mathrm{M}, 5 \square \mathrm{min})$ application in brain slices from Emx1-Ai32 mice. (E-F) Protein translation inhibition blocked corticostriatal MOR-LTD (105 \pm 9\%) with no effects in oEPSC amplitude after DAMGO bath application (0-10 $\square$ min baseline v. final $10 \square$ min of recording; paired t-test, $\mathrm{P} \square=\square 0.4992, \mathrm{t} 7 \square=0.713, \mathrm{n} \square=8$ neurons from 3 mice). (G) Representative AIC-DLS oEPSC traces showing the effects of $80 \mu \mathrm{M}$ cycloheximide before, during and after DAMGO $(0.3 \square \mu \mathrm{M}, 5 \square \mathrm{min})$ application. (H-I) Protein translation is needed to induce MOR-LTD (91 $\pm 2 \%)$ from AIC inputs. DAMGO did not change in oEPSC amplitude (0-10 $\square$ min baseline v. final $10 \square \mathrm{min}$ of recording; paired t-test, $\mathrm{P} \square=\square 0.1208, \mathrm{t} 5 \square=1.868, \mathrm{n} \square=6$ neurons from 2 mice). Data represent 

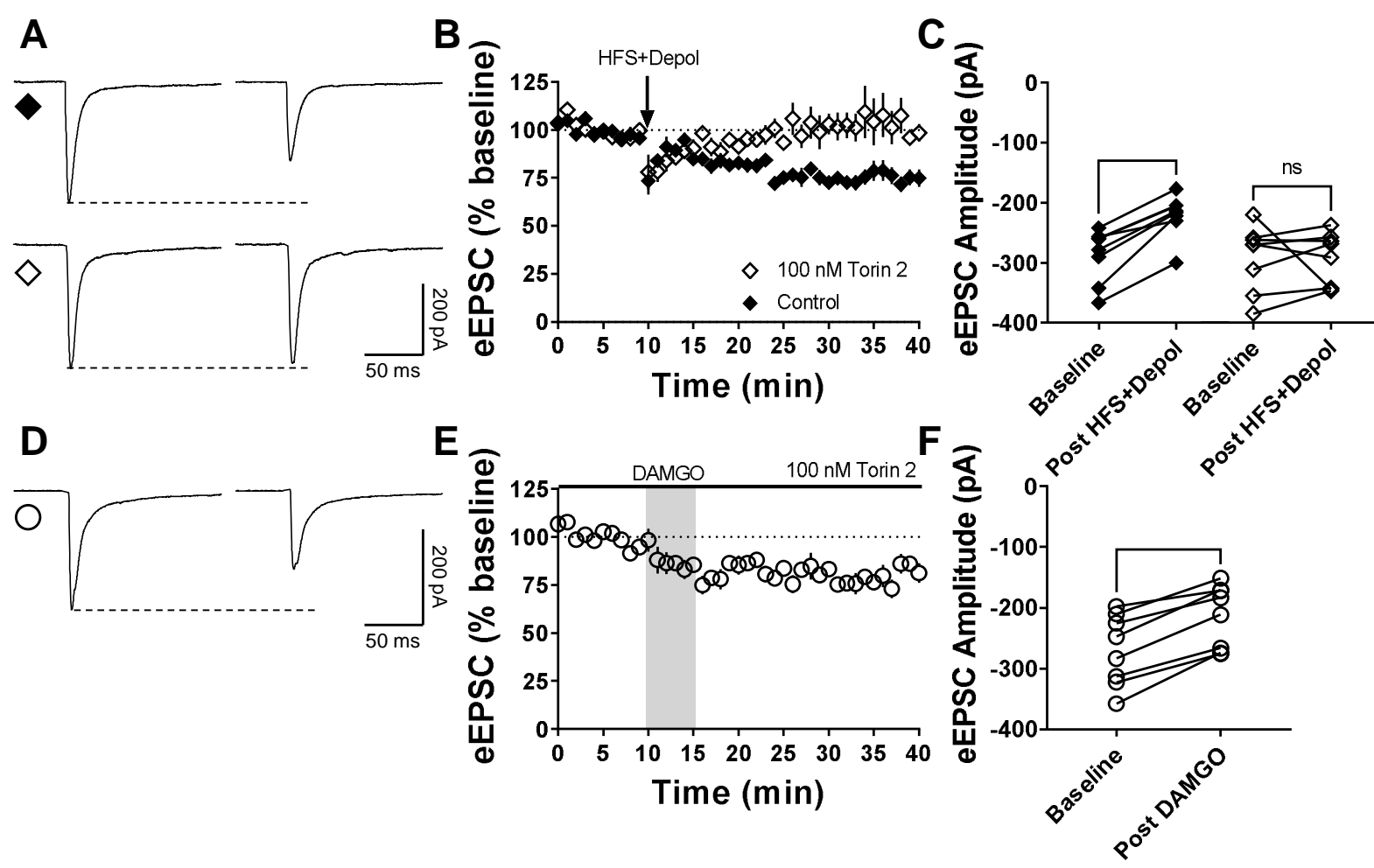

Figure 6. mTOR pathway is involve in eCB-LTD but not in MOR-LTD in the DLS. (A) Representative eEPSC traces before and after high-frequency stimulation (HFS) coupled with depolarization (4 pulses of $100 \square \mathrm{Hz}, 10 \square$ s inter-pulse interval), showing the effects of torin $2(100 \mathrm{nM})$ bath application in brain slices of C57BL/J. (B-C) mTOR inhibition blocked eCB-LTD in DLS $(0-10 \square \mathrm{min}$ baseline v. final $10 \square \mathrm{min}$ of recording; Control: paired t-test, $\mathrm{P} \square=\square 0.0002, \mathrm{t} 7 \square=7.08, \mathrm{n} \square=8$ neurons from 3 mice; torin 2: paired t-test, $\mathrm{P} \square=\square 0.9009, \mathrm{t} 7 \square=0.129, \mathrm{n} \square=8$ neurons from 3 mice). (D) Representative eEPSC traces before and after DAMGO bath application $(0.3 \square \mu \mathrm{M}, 5 \square \mathrm{min})$, showing the effects of torin $2(100 \mathrm{nM})$ bath application in brain slices of C57BL/J. (E-F) mTOR inhibition did not affect the expression of MOR-LTD in DLS (0-10 $\square$ min baseline v. final $10 \square$ min of recording; paired t-test, $\mathrm{P} \square<\square 0.0001, \mathrm{t} 7 \square=8.11, \mathrm{n} \square=8$ neurons from 3 mice). Data represent mean \pm SEM. ${ }^{* * *} \mathrm{P} \square<\square 0.001,{ }^{* * * *} \mathrm{P} \square<\square 0.0001$. 

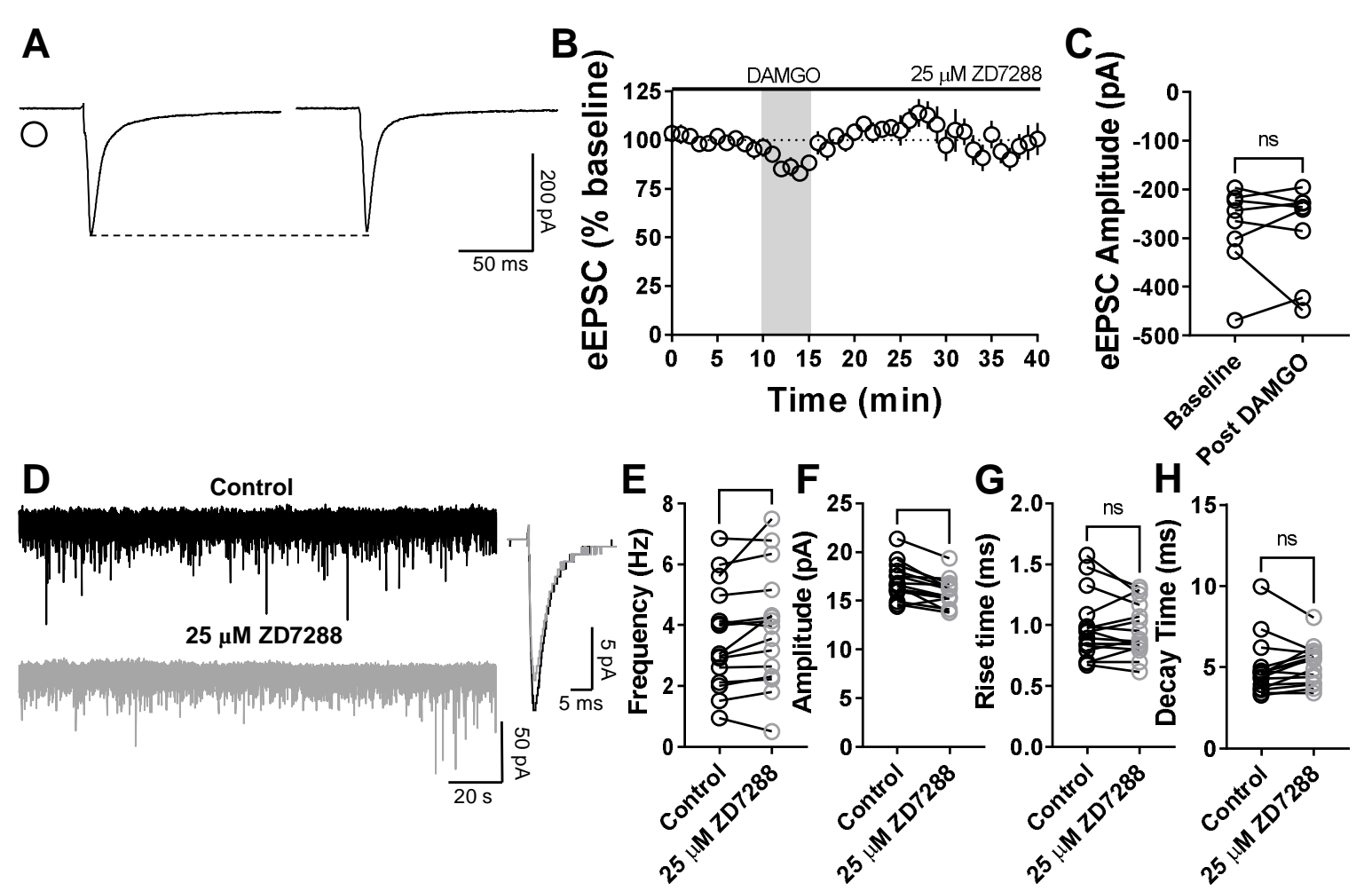

Figure 7. Inhibition of HCN channels disrupts MOR-mediated LTD. (A) Representative eEPSC traces showing the effects of $25 \mu \mathrm{M}$ ZD7288 before, during and after DAMGO $(0.3 \square \mu \mathrm{M}, 5 \square \mathrm{min})$ application. (B-C) HCN channel inhibition disrupted glutamatergic MOR-LTD (104 $\pm 9 \%)$ in the DLS, showing no changes in eEPSC amplitude after DAMGO bath application $(0-10 \square \mathrm{min}$ baseline $\mathrm{v}$. final $10 \square \mathrm{min}$ of recording; paired t-test, $\mathrm{P} \square=\square 0.8008, \mathrm{t} 7 \square=0.2621, \mathrm{n} \square=8$ neurons from 5 mice). (D) Representative synaptic current traces from C57BL/6J mice showing the spontaneous excitatory postsynaptic currents (sEPSC) in absence (black trace) or presence of $25 \mu \mathrm{M}$ ZD7288 (gray trace, $15 \mathrm{~min}$ ) application. (E-H) HCN channel inhibition increased frequency (paired t-test, $\mathrm{P} \square=\square 0.043, \mathrm{t} 14 \square=2.223, \mathrm{n} \square=15$ neurons from 2 mice) and decreased amplitude (paired t-test, $\mathrm{P} \square=\square 0.0005$, $\mathrm{t} 14 \square=4.49, \mathrm{n} \square=15$ neurons from 2 mice), without changes in rise (paired t-test, $\mathrm{P} \square=\square 0.542$, $\mathrm{t} 14 \square=0.625, \mathrm{n} \square=15$ neurons from 2 mice) and decay times (paired t-test, $\mathrm{P} \square=\square 0.324, \mathrm{t} 14 \square=1.023, \mathrm{n} \square=15$ neurons from 2 mice) of the SEPSC events in DLS. Data represent mean $\pm S E M$. ns $=$ no significant, ${ }^{*} \mathrm{P} \square<\square 0.05,{ }^{* * *} \mathrm{P} \square<\square 0.001$. 
A

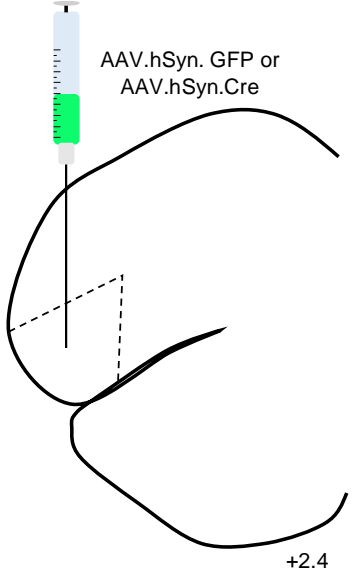

B

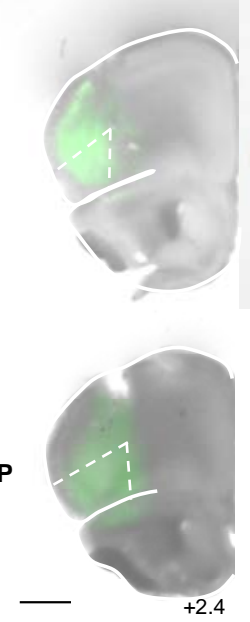

E

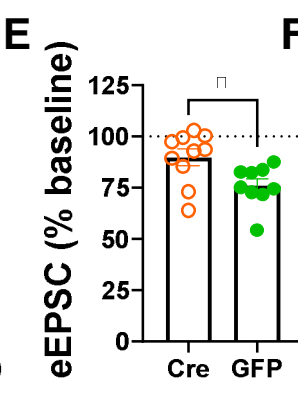

D

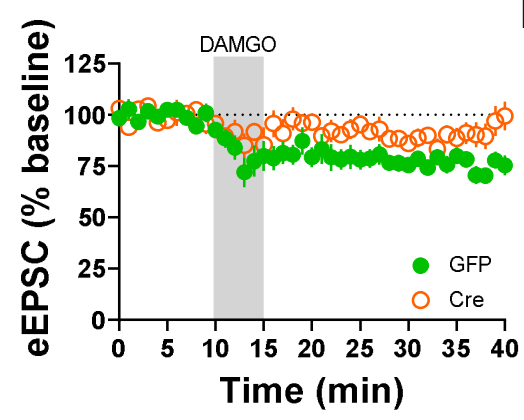

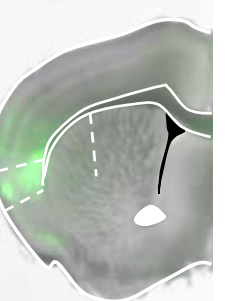

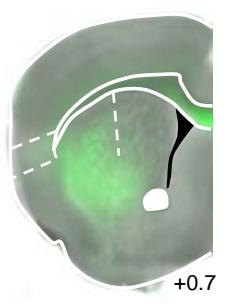

$F$
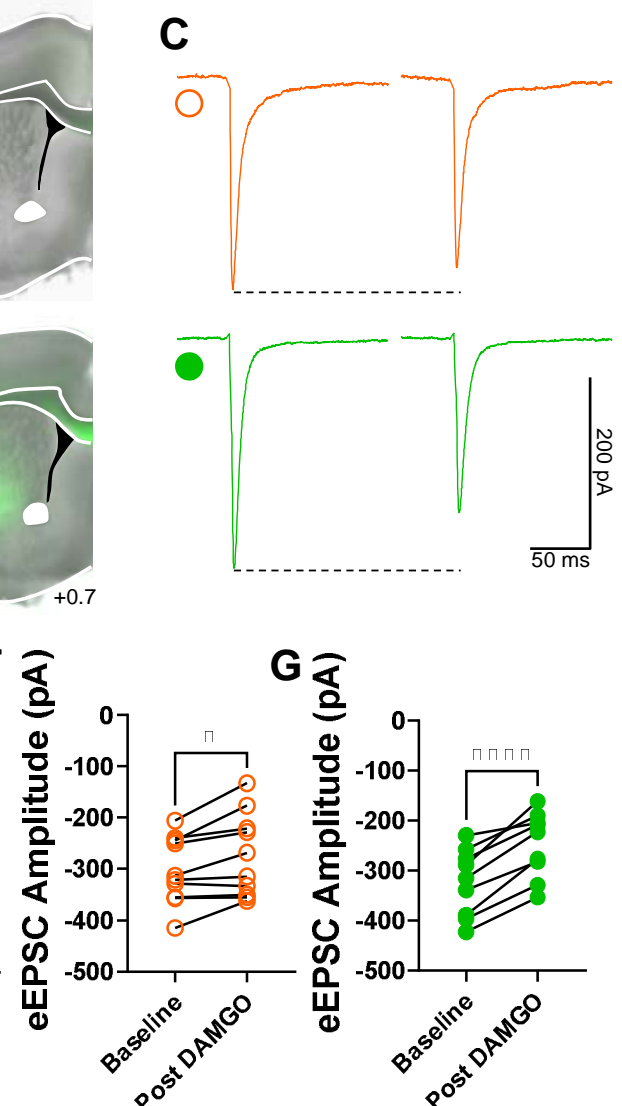

$\mathrm{G} \overline{\mathrm{s}}$

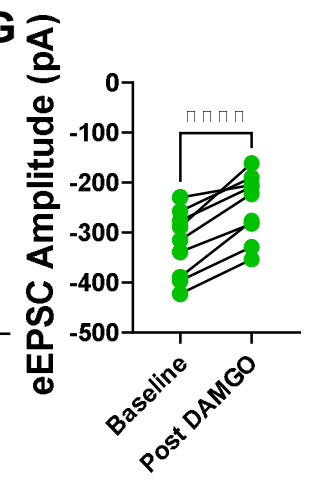

$\mathbf{H}$

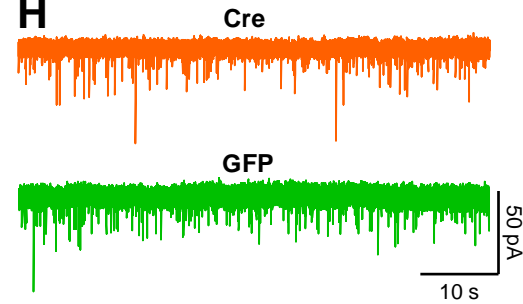

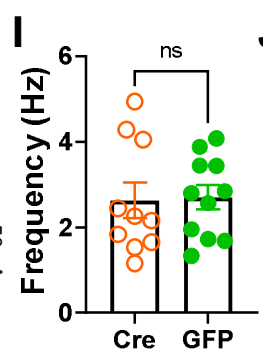
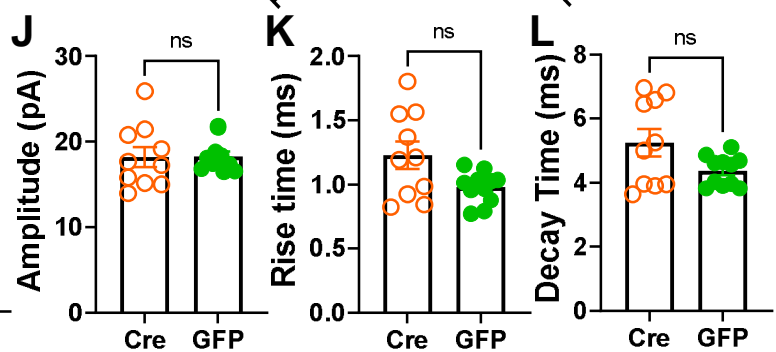

Figure 8. Genetic ablation of HCN1 channels reduces MOR-mediated LTD expression. (A) Schematic figure of coronal brain slice showing injection paradigm enabling knock out of HCN1 channel expression in AIC in HCN1-flox mice. An AAV vector encoding for either cre-recombinase (AAV.hSyn.cre) or eGFP (AAV.hSyn.eGFP) was injected at least 4 weeks prior to recordings. (B) Coronal brain slice showing the AAV-cre or AAV-GFP infection of AIC and dorsal striatal terminal expression (bar scale $\square=\square 1000 \square \mu \mathrm{m}$ ). (C) Representative eEPSC traces showing the effects of DAMGO $(0.3 \square \mu \mathrm{M}, 5 \square \mathrm{min})$ application in brain slices of AAV-injected HCN1-flox mice. (D-E) The conditional KO of HCN1 channel from AIC, blunted MOR-LTD in DLS (cre: $90 \pm 4 \%$ vs GFP: $76 \pm 3 \%$, Unpaired t-test, $\mathrm{P}=0.017, \mathrm{t} 17=2.64, \mathrm{n}=10$ neurons from 5 cre-injected mice and $n=9$ neurons from 3 GFP-injected mice). (F) HCN1 deletion did not fully disrupt MOR-LTD, because there was still a small, but significant reduction of eEPSC amplitude after DAMGO application (0-10 $\square$ min baseline v. final $10 \square \mathrm{min}$ of recording; 
638

639

640

641

642

643

644

645

646

647

648

649

650

651

652

653

654 paired t-test, $\mathrm{P} \square=\square 0.011$, $\mathrm{t} 9 \square=3.18, \mathrm{n} \square=10$ neurons from 5 mice). (G) Control GFP. injected mice showed normal decrease of eEPSC amplitude after DAMGO application 0-10 $\square$ min baseline v. final $10 \square$ min of recording; paired t-test, $\mathrm{P} \square<\square 0.0001, \mathrm{t} \square \square=7.51$, $\mathrm{n} \square=9$ neurons from 3 mice). (H) Representative synaptic current traces from HCN1-flox mice showing the spontaneous excitatory postsynaptic currents (sEPSCs) in AAV-cre (orange trace) and AAV-GFP (green trace) injected mice. (I-L) HCN1 channel ablation from AIC synapses did not affect frequency (cre: $2.6 \pm 0.4 \mathrm{~Hz}$ vs GFP: $2.7 \pm 0.3 \mathrm{~Hz}$, Unpaired t-test, $P=0.886, t 19=0.146, n=10$ neurons from 3 cre-injected mice and $n=11$ neurons from 2 GFP-injected mice), amplitude (cre: $18.2 \pm 1.2$ pA vs GFP: $18.3 \pm 0.6$ $\mathrm{pA}$, Unpaired t-test with Welch's correction, $\mathrm{P}=0.957, \mathrm{t} 13=0.055, \mathrm{n}=10$ neurons from 3 cre-injected mice and $n=11$ neurons from 2 GFP-injected mice), rise time (cre: $1.23 \pm$ $0.11 \mathrm{~ms}$ vs GFP: $0.98 \pm 0.04 \mathrm{~ms}$, Unpaired t-test with Welch's correction, $\mathrm{P}=0.0501$, $\mathrm{t} 11=2.19, \mathrm{n}=10$ neurons from 3 cre-injected mice and $\mathrm{n}=11$ neurons from 2 GFPinjected mice) and decay time (cre: $5.25 \pm 0.43$ ms vs GFP: $4.36 \pm 0.14$ ms, Unpaired ttest with Welch's correction, $P=0.075, t 11=1.97, n=10$ neurons from 3 cre-injected mice and $n=11$ neurons from 2 GFP-injected mice) of the sEPSC events in DLS. Data represent mean \pm SEM. ns $=$ no significant, ${ }^{*} \mathrm{P} \square<\square 0.05,{ }^{\star \star *}{ }^{*} \mathrm{P} \square<\square 0.0001$. 


\section{References}

656

657

658

659

660

661

662

663

664

665

666

667

668

669

670

671

672

673

674

675

676

677

678

679

680

681

682

683

684

685

686

687

688

689

690

691

692

693

694

695

696

697

698

699

700

Adermark, L. (2011). Modulation of endocannabinoid-mediated long-lasting disinhibition of striatal output by cholinergic interneurons. Neuropharmacology, 61(8), 1314-1320. doi:https://doi.org/10.1016/i.neuropharm.2011.07.039

Adermark, L., Talani, G., \& Lovinger, D. M. (2009). Endocannabinoid-dependent plasticity at GABAergic and glutamatergic synapses in the striatum is regulated by synaptic activity. The European journal of neuroscience, 29(1), 32-41. doi:10.1111/j.1460-9568.2008.06551.x

Atwood, B. K., Kupferschmidt, D. A., \& Lovinger, D. M. (2014). Opioids induce dissociable forms of longterm depression of excitatory inputs to the dorsal striatum. Nat Neurosci, 17(4), 540-548. doi:10.1038/nn.3652

Atwood, B. K., Lovinger, D. M., \& Mathur, B. N. (2014). Presynaptic long-term depression mediated by Gi/o-coupled receptors. Trends Neurosci, 37(11), 663-673. doi:10.1016/j.tins.2014.07.010

Bao, G., Kang, L., Li, H., Li, Y., Pu, L., Xia, P., . . Pei, G. (2007). Morphine and heroin differentially modulate in vivo hippocampal LTP in opiate-dependent rat. Neuropsychopharmacology, 32(8), 1738-1749. doi:10.1038/sj.npp.1301308

Boyes, J., Bolam, J. P., Shigemoto, R., \& Stanford, I. M. (2007). Functional presynaptic HCN channels in the rat globus pallidus. European Journal of Neuroscience, 25(7), 2081-2092. doi:https://doi.org/10.1111/i.1460-9568.2007.05463.x

Burton, A. C., Nakamura, K., \& Roesch, M. R. (2015). From ventral-medial to dorsal-lateral striatum: neural correlates of reward-guided decision-making. Neurobiol Learn Mem, 117, 51-59. doi:10.1016/j.nlm.2014.05.003

Chen, I., \& Lui, F. (2021). Neuroanatomy, Neuron Action Potential. In StatPearls. Treasure Island (FL): StatPearls Publishing

Copyright (C 2021, StatPearls Publishing LLC.

Cho, H. S., Lee, H. H., Choi, S. J., Kim, K. J., Jeun, S. H., Li, Q.-Z., \& Sung, K.-W. (2008). Forskolin Enhances Synaptic Transmission in Rat Dorsal Striatum through NMDA Receptors and PKA in Different Phases. kjpp, 12(6), 293-297. doi:10.4196/kjpp.2008.12.6.293

Corbit, L. H., \& Janak, P. H. (2016). Habitual Alcohol Seeking: Neural Bases and Possible Relations to Alcohol Use Disorders. Alcoholism: Clinical and Experimental Research, 40(7), 1380-1389. doi:10.1111/acer.13094

Dacher, M., \& Nugent, F. S. (2011a). Morphine-induced modulation of LTD at GABAergic synapses in the ventral tegmental area. Neuropharmacology, 61(7), 1166-1171. doi:10.1016/j.neuropharm.2010.11.012

Dacher, M., \& Nugent, F. S. (2011b). Opiates and plasticity. Neuropharmacology, 61(7), 1088-1096. doi:10.1016/j.neuropharm.2011.01.028

DePoy, L., Daut, R., Brigman, J. L., MacPherson, K., Crowley, N., Gunduz-Cinar, O., . . Holmes, A. (2013). Chronic alcohol produces neuroadaptations to prime dorsal striatal learning. Proc Natl Acad Sci U S A, 110(36), 14783-14788. doi:10.1073/pnas.1308198110

Drake, C. T., Chavkin, C., \& Milner, T. A. (2007). Opioid systems in the dentate gyrus. Prog Brain Res, 163, 245-263. doi:10.1016/s0079-6123(07)63015-5

Everitt, B. J., \& Robbins, T. W. (2016). Drug Addiction: Updating Actions to Habits to Compulsions Ten Years On. Annual Review of Psychology, 67(1), 23-50. doi:10.1146/annurev-psych-122414033457

Frank, C. A., Pielage, J., \& Davis, G. W. (2009). A presynaptic homeostatic signaling system composed of the Eph receptor, ephexin, Cdc42, and CaV2.1 calcium channels. Neuron, 61(4), 556-569. doi:10.1016/j.neuron.2008.12.028 
Fritz, B. M., Munoz, B., \& Atwood, B. K. (2019). Genetic Selection for Alcohol Preference in Mice Alters Dorsal Striatum Neurotransmission. Alcohol Clin Exp Res, 43(11), 2312-2321. doi:10.1111/acer.14187

Fritz, B. M., Munoz, B., Yin, F., Bauchle, C., \& Atwood, B. K. (2018). A High-fat, High-sugar 'Western' Diet Alters Dorsal Striatal Glutamate, Opioid, and Dopamine Transmission in Mice. Neuroscience, 372, 1-15. doi:10.1016/j.neuroscience.2017.12.036

Gremel, C. M., Chancey, J. H., Atwood, B. K., Luo, G., Neve, R., Ramakrishnan, C., . . Costa, R. M. (2016). Endocannabinoid Modulation of Orbitostriatal Circuits Gates Habit Formation. Neuron, 90(6), 1312-1324. doi:10.1016/j.neuron.2016.04.043

Hawes, S. L., Salinas, A. G., Lovinger, D. M., \& Blackwell, K. T. (2017). Long-term plasticity of corticostriatal synapses is modulated by pathway-specific co-release of opioids through $\mathrm{k}$-opioid receptors. J Physiol, 595(16), 5637-5652. doi:10.1113/jp274190

He, C., Chen, F., Li, B., \& Hu, Z. (2014). Neurophysiology of HCN channels: from cellular functions to multiple regulations. Prog Neurobiol, 112, 1-23. doi:10.1016/j.pneurobio.2013.10.001

Hilário, M. R. F., \& Costa, R. M. (2008). High on habits. Frontiers in neuroscience, 2(2), 208-217. doi:10.3389/neuro.01.030.2008

Hopf, F. W., \& Lesscher, H. M. B. (2014). Rodent models for compulsive alcohol intake. Alcohol, 48(3), 253-264. doi:https://doi.org/10.1016/j.alcohol.2014.03.001

Huang, Z., Li, G., Aguado, C., Lujan, R., \& Shah, M. M. (2017). HCN1 channels reduce the rate of exocytosis from a subset of cortical synaptic terminals. Sci Rep, 7, 40257. doi:10.1038/srep40257

Huang, Z., Lujan, R., Kadurin, I., Uebele, V. N., Renger, J. J., Dolphin, A. C., \& Shah, M. M. (2011). Presynaptic HCN1 channels regulate CaV3.2 activity and neurotransmission at select cortical synapses. Nature Neuroscience, 14(4), 478-486. doi:10.1038/nn.2757

Iremonger, K. J., \& Bains, J. S. (2009). Retrograde opioid signaling regulates glutamatergic transmission in the hypothalamus. J Neurosci, 29(22), 7349-7358. doi:10.1523/jneurosci.0381-09.2009

Le Merrer, J., Becker, J. A. J., Befort, K., \& Kieffer, B. L. (2009). Reward processing by the opioid system in the brain. Physiological reviews, 89(4), 1379-1412. doi:10.1152/physrev.00005.2009

Lonart, G., Schoch, S., Kaeser, P. S., Larkin, C. J., Südhof, T. C., \& Linden, D. J. (2003). Phosphorylation of RIM1alpha by PKA triggers presynaptic long-term potentiation at cerebellar parallel fiber synapses. Cell, 115(1), 49-60. doi:10.1016/s0092-8674(03)00727-x

Lovinger, D. M. (2010). Neurotransmitter roles in synaptic modulation, plasticity and learning in the dorsal striatum. Neuropharmacology, 58(7), 951-961. doi:10.1016/j.neuropharm.2010.01.008

Mato, S., Lafourcade, M., Robbe, D., Bakiri, Y., \& Manzoni, O. J. (2008). Role of the cyclic-AMP/PKA cascade and of $\mathrm{P} / \mathrm{Q}$-type $\mathrm{Ca++}$ channels in endocannabinoid-mediated long-term depression in the nucleus accumbens. Neuropharmacology, 54(1), 87-94. doi:10.1016/j.neuropharm.2007.04.014

Moosmang, S., Biel, M., Hofmann, F., \& Ludwig, A. (1999). Differential distribution of four hyperpolarization-activated cation channels in mouse brain. Biol Chem, 380(7-8), 975-980. doi:10.1515/BC.1999.121

Munoz, B., Fritz, B. M., Yin, F., \& Atwood, B. K. (2018). Alcohol exposure disrupts mu opioid receptormediated long-term depression at insular cortex inputs to dorsolateral striatum. Nat Commun, 9(1), 1318. doi:10.1038/s41467-018-03683-1

Muñoz, B., Haggerty, D. L., \& Atwood, B. K. (2020). Synapse-specific expression of mu opioid receptor long-term depression in the dorsomedial striatum. Scientific Reports, 10(1), 7234. doi:10.1038/s41598-020-64203-0

Nazzaro, C., Greco, B., Cerovic, M., Baxter, P., Rubino, T., Trusel, M., . . . Tonini, R. (2012). SK channel modulation rescues striatal plasticity and control over habit in cannabinoid tolerance. Nat Neurosci, 15(2), 284-293. doi:10.1038/nn.3022 
Nazzaro, C., Greco, B., Cerovic, M., Baxter, P., Rubino, T., Trusel, M., . . . Tonini, R. (2012). SK channel modulation rescues striatal plasticity and control over habit in cannabinoid tolerance. Nature Neuroscience, 15(2), 284-293. doi:10.1038/nn.3022

O'Tousa, D., \& Grahame, N. (2014). Habit formation: Implications for alcoholism research. Alcohol, 48(4), 327-335. doi:https://doi.org/10.1016/i.alcohol.2014.02.004

Patton, M. H., Roberts, B. M., Lovinger, D. M., \& Mathur, B. N. (2016). Ethanol Disinhibits Dorsolateral Striatal Medium Spiny Neurons Through Activation of A Presynaptic Delta Opioid Receptor. Neuropsychopharmacology, 41(7), 1831-1840. doi:10.1038/npp.2015.353

Plotkin, J. L., Shen, W., Rafalovich, I., Sebel, L. E., Day, M., Chan, C. S., \& Surmeier, D. J. (2013). Regulation of dendritic calcium release in striatal spiny projection neurons. J Neurophysiol, 110(10), 2325-2336. doi:10.1152/jn.00422.2013

Postea, O., \& Biel, M. (2011). Exploring HCN channels as novel drug targets. Nat Rev Drug Discov, 10(12), 903-914. doi:10.1038/nrd3576

Renteria, R., Cazares, C., \& Gremel, C. M. (2020). Habitual Ethanol Seeking and Licking Microstructure of Enhanced Ethanol Self-Administration in Ethanol-Dependent Mice. Alcoholism, clinical and experimental research, 44(4), 880-891. doi:10.1111/acer.14302

Salling, M. C., \& Harrison, N. L. (2020). Constitutive Genetic Deletion of Hcn1 Increases Alcohol Preference during Adolescence. Brain Sci, 10(11). doi:10.3390/brainsci10110763

Sartiani, L., Mannaioni, G., Masi, A., Novella Romanelli, M., \& Cerbai, E. (2017). The HyperpolarizationActivated Cyclic Nucleotide-Gated Channels: from Biophysics to Pharmacology of a Unique Family of Ion Channels. Pharmacological Reviews, 69(4), 354-395. doi:10.1124/pr.117.014035

Shen, F., Jin, S., Duan, Y., Liang, J., Zhang, M., Jiang, F., \& Sui, N. (2018). Distinctive Changes of L-Type Calcium Channels and Dopamine Receptors in the Dorsomedial and Dorsolateral Striatum after the Expression of Habitual Cocaine-Seeking Behavior in Rats. Neuroscience, 370, 139-147. doi:10.1016/j.neuroscience.2017.07.049

Tanimura, A., Yamazaki, M., Hashimotodani, Y., Uchigashima, M., Kawata, S., Abe, M., . . Kano, M. (2010). The Endocannabinoid 2-Arachidonoylglycerol Produced by Diacylglycerol Lipase $\alpha$ Mediates Retrograde Suppression of Synaptic Transmission. Neuron, 65(3), 320-327. doi:https://doi.org/10.1016/j.neuron.2010.01.021

Tien, N.-W., \& Kerschensteiner, D. (2018). Homeostatic plasticity in neural development. Neural Development, 13(1), 9. doi:10.1186/s13064-018-0105-x

Wang, Z., Kai, L., Day, M., Ronesi, J., Yin, H. H., Ding, J., . . Surmeier, D. J. (2006). Dopaminergic Control of Corticostriatal Long-Term Synaptic Depression in Medium Spiny Neurons Is Mediated by Cholinergic Interneurons. Neuron, 50(3), 443-452. doi:https://doi.org/10.1016/i.neuron.2006.04.010

Wu, Y. W., Kim, J. I., Tawfik, V. L., Lalchandani, R. R., Scherrer, G., \& Ding, J. B. (2015). Input- and celltype-specific endocannabinoid-dependent LTD in the striatum. Cell reports, 10(1), 75-87. doi:10.1016/j.celrep.2014.12.005

Yasuda, H., Huang, Y., \& Tsumoto, T. (2008). Regulation of excitability and plasticity by endocannabinoids and PKA in developing hippocampus. Proceedings of the National Academy of Sciences, 105(8), 3106-3111. doi:10.1073/pnas.0708349105

Yin, H. H., Davis, M. I., Ronesi, J. A., \& Lovinger, D. M. (2006). The Role of Protein Synthesis in Striatal Long-Term Depression. The Journal of Neuroscience, 26(46), 11811-11820. doi:10.1523/jneurosci.3196-06.2006

Younts, T. J., Monday, H. R., Dudok, B., Klein, M. E., Jordan, B. A., Katona, I., \& Castillo, P. E. (2016). Presynaptic Protein Synthesis Is Required for Long-Term Plasticity of GABA Release. Neuron, 92(2), 479-492. doi:10.1016/j.neuron.2016.09.040 
bioRxiv preprint doi: https://doi.org/10.1101/2021.08.31.458358; this version posted September 1, 2021. The copyright holder for this preprint (which was not certified by peer review) is the author/funder, who has granted bioRxiv a license to display the preprint in perpetuity. It is made available under aCC-BY-NC 4.0 International license.

796 